\title{
Dual Responses of CNS Mitochondria to Elevated Calcium
}

\author{
Nickolay Brustovetsky and Janet M. Dubinsky \\ Departments of Physiology and Neuroscience, University of Minnesota, Minneapolis, Minnesota 55455
}

\begin{abstract}
Isolated brain mitochondria were examined for their responses to calcium challenges under varying conditions. Mitochondrial membrane potential was monitored by following the distribution of tetraphenylphosphonium ions in the mitochondrial suspension, mitochondrial swelling by observing absorbance changes, calcium accumulation by an external calcium electrode, and oxygen consumption with an oxygen electrode. Both the extent and rate of calcium-induced mitochondrial swelling and depolarization varied greatly depending on the energy source provided to the mitochondria. When energized with succinate plus glutamate, after a calcium challenge, CNS mitochondria depolarized transiently, accumulated substantial calcium, and increased in volume, characteristic of a mitochondrial permeability transition. When energized with $3 \mathrm{~mm}$ succinate, CNS mitochondria maintained a sustained calciuminduced depolarization without appreciable swelling and were
\end{abstract}

slow to accumulate calcium. Maximal oxygen consumption was also restricted under these conditions, preventing the electron transport chain from compensating for this increased proton permeability. In $3 \mathrm{~mm}$ succinate, cyclosporin A and ADP plus oligomycin restored potential and calcium uptake. This low conductance permeability was not effected by bongkrekic acid or carboxyatractylate, suggesting that the adenine nucleotide translocator was not directly involved. Fura-2FF measurements of $\left[\mathrm{Ca}^{2+}\right]_{\mathrm{i}}$ suggest that in cultured hippocampal neurons glutamate-induced increases reached tens of micromolar levels, approaching those used with mitochondria. We propose that in the restricted substrate environment, $\mathrm{Ca}^{2+}$ activated a low-conductance permeability pathway responsible for the sustained mitochondrial depolarization.

Key words: permeability transition; mitochondria; fura-2FF; tetraphenylphosphonium; calcium; neurodegeneration
The mitochondrial permeability transition ( $\mathrm{mPT})$ is a candidate mediator of both necrotic and apoptotic cell death (Schinder et al., 1996; Dubinsky and Levi, 1998; Hirsch et al., 1998). In neurodegeneration, the $\mathrm{mPT}$ has been implicated in primary neuronal cultures exposed to excitotoxins (Ankarcrona et al., 1996; Schinder et al., 1996; White and Reynolds, 1996; Kristal and Dubinsky, 1997; Dubinsky and Levi, 1998; Stout et al., 1998), genetically altered cell lines mimicking chronic neurodegenerative conditions (Keller et al., 1998), reconstituted cell-free apoptotic systems (Ellerby et al., 1997), in vivo models of acute neuronal insults (Folbergrova et al., 1997; Li et al., 1997; Friberg et al., 1998), and exposure to neurotoxins (Cassarino et al., 1998). These neurotoxicities are hypothesized to stem from elevations of cytosolic $\mathrm{Ca}^{2+}$ activating the $\mathrm{mPT}$, a nonselective, multiconductance pore in the inner mitochondrial membrane, with consequent mitochondrial swelling and dysfunction (Zoratti and Szabo, 1995). Subsequent release of mitochondrial proteins, cytochrome $c$ and apoptosis-inducing factor, would trigger nuclear degradation (Liu et al., 1996; Zamzami et al., 1996). However, release of cytochrome $c$ may occur without mitochondrial swelling (Andreyev et al., 1998; Eskes et al., 1998; Murphy et al., 1998; Shimizu et al., 1999). Reversible opening of a low-conductance

\footnotetext{
Received Aug. 23, 1999; revised Oct. 12, 1999; accepted Oct. 14, 1999.

This work was supported by National Institute on Aging Grant AG10034 to J.M.D. and by American Heart Association Fellowship (Minnesota Affiliates) 9804691X to N.B. We thank Dr. Vincent Barnett for use of his spectrophotometer. Drs. G. Engel and H. Widmer of Sandoz Pharma Ltd. kindly provided the CsA, and Dr. M. Klingenberg graciously provided the BKA and CAT.

Correspondence should be addressed to Dr. Janet M. Dubinsky, University of Minnesota, Department of Neuroscience, 6-145 Jackson Hall, 321 Church Street SE, Minneapolis, MN, 55455. E-mail: dubin001@tc.umn.edu.

Dr. Brustovetsky's permanent address: Institute of Theoretical and Experimental Biophysics, Russian Academy of Science, Pushchino 142292, Moscow Region, Russia. Copyright (C) 1999 Society for Neuroscience $0270-6474 / 99 / 200103-11 \$ 15.00 / 0$
}

pathway in the inner mitochondrial membrane has also been postulated to trigger cytochrome $c$ release (Green and Reed, 1998; Zamzami et al., 1998).

Operation of the liver $\mathrm{mPT}$ in a low-conductance mode can lead to mitochondrial calcium-induced calcium release (Ichas et al., 1997). In liver and heart mitochondria, a low-conductance state of the mPT may precede and remain open after closure of a calcium-induced large conductance pore associated with mitochondrial swelling (Broekemeier et al., 1985, 1998; Al-Nasser and Crompton, 1986). Moreover, $\mathrm{K}^{+}$efflux precedes $\mathrm{Mg}^{2+}$ release and both precede mannitol-sucrose influx and swelling (Broekemeier and Pfeiffer, 1995). Using a $\mathrm{TPP}^{+}$electrode and ${ }^{14} \mathrm{C}$ sucrose matrix entrapment, a cyclosporin A (CsA)-sensitive, proton-specific permeability increase can be completely separated from a $\mathrm{Ca}^{2+}$ plus $\mathrm{P}_{\mathrm{i}}$-induced nonspecific permeability (Crompton et al., 1988). Morphological assessments revealed that glutathione release, associated with a collapse of $\Delta \psi$, was attributable to a uniform induction of a low-conductance $\mathrm{mPT}$ throughout the entire mitochondrial population (Savage and Reed, 1994). Singlechannel recordings of inner mitochondrial membrane channels with multiple conductance levels further suggests the mPT pore has both low- and high-conductance states (Kinnaly et al., 1989; Szabo and Zoratti, 1989).

In contrast, only high-conductance $\mathrm{mPT}$ operation has been reported in brain mitochondria (Kristal and Dubinsky, 1997; Andreyev et al., 1998; Dubinsky and Levi, 1998). In our previous studies, the extent of mitochondrial swelling varied in different oxidative substrates. We hypothesized that variations in energy supply might influence the probability of classical, highconductance mPT induction. Surprisingly, in conditions of restricted oxidative activity, $\mathrm{Ca}^{2+}$ induced mitochondrial depolarizations without concomitant swelling. The inner mitochondrial 
membrane permeability underlying this phenomenon could represent a substrate of the $\mathrm{mPT}$ pore or a novel $\mathrm{Ca}^{2+}$-activated conductance.

\section{MATERIALS AND METHODS}

Isolation of brain mitochondria. Brain mitochondria were isolated as described by Takeuchi et al. (1991) with some modifications. Briefly, an adult rat brain was rapidly removed according to an Institutional Animal Care and Use Committee-approved protocol and immediately put into ice-cold isolation medium containing $225 \mathrm{~mm}$ mannitol, $75 \mathrm{~mm}$ sucrose, $0.1 \%$ bovine serum albumin (BSA; free fatty acid-free), $1 \mathrm{~mm}$ EGTA, and $10 \mathrm{mM}$ HEPES, pH 7.4. The tissue was washed with the isolation medium, dissected, and homogenized with $20 \mathrm{ml}$ of the isolation medium in a Dounce-type homogenizer. The homogenate was centrifuged at $2000 \times g$ for $10 \mathrm{~min}$ at $2^{\circ} \mathrm{C}$. The supernatant was then centrifuged at $12,000 \times g$ for $10 \mathrm{~min}$. The pellet was resuspended in $20 \mathrm{ml}$ of the medium containing (in mM): 225 mannitol, 75 sucrose, 0.1 EGTA, and 10 HEPES, $\mathrm{pH} 7.4$, and centrifuged again at $12,000 \mathrm{gm}$ for $10 \mathrm{~min}$ at $2^{\circ} \mathrm{C}$. The pellet was resuspended to a final volume of $1 \mathrm{ml}$ in the latter medium and used for the respiration, $\Delta \psi$, and $\mathrm{Ca}^{2+}$ transport measurements. This preparation provided sufficient mitochondria with a high respiratory control ratio, stable $\Delta \psi$, and the ability to accumulate $\mathrm{Ca}^{2+}$ for multiple experiments to be performed in a single afternoon. For the absorbance assay, the presence of synaptosomes may mask volume changes of isolated mitochondria. Therefore, to observe mitochondrial swelling in absorbance assays, brain mitochondria were further purified on a discontinuous Percoll gradient to remove synaptosomes (Kristal and Dubinsky, 1997). The lower yield of mitochondria obtained after this purification $(200 \mu \mathrm{l}$ of $10-15 \mathrm{mg}$ of protein $/ \mathrm{ml})$ precluded its use for experiments involving multiple comparisons or replications. However, the main results obtained with the unpurified mitochondria were confirmed in the gradient-purified mitochondria.

Measurements of $\Delta \psi$. The experiments with isolated brain mitochondria were performed in a standard incubation medium containing (in $\mathrm{mM}): 215$ mannitol, 50 sucrose, $10 \mathrm{KCl}, 3 \mathrm{KH}_{2} \mathrm{PO}_{4}, 0.5 \mathrm{MgCl}_{2}, 10$ HEPES, and the indicated substrate or substrates, $\mathrm{pH} 7.4$ at $30^{\circ} \mathrm{C}$ under continuous stirring in a thermostated, $2.0 \mathrm{ml}$ chamber. The concentration of protein in the chamber was $2.0-2.5 \mathrm{mg} / \mathrm{ml}$, determined by the Bradford (1976) method. $\Delta \psi$ was followed by monitoring the distribution of tetraphenylphosphonium cation $\left(\mathrm{TPP}^{+}\right)$between the external medium (initially $1.8 \mu \mathrm{M} \mathrm{TPP}{ }^{+}-\mathrm{Cl}$ ) and the mitochondrial matrix with a $\mathrm{TPP}^{+}$sensitive electrode (Kamo et al., 1979). A decrease in the absolute value of $\Delta \psi$ is referred to as a depolarization or a decrease in $\Delta \psi$. The response of the $\mathrm{TPP}^{+}$electrode was logarithmic so that at high external $\left[\mathrm{TPP}^{+}\right]$, a small deviation represented many more millivolts of difference than at low external $\left[\mathrm{TPP}^{+}\right]$. Similar results were obtained in $100 \mathrm{mM} \mathrm{KCl}$ medium in which any synaptosomal membrane potential should be negligible.

Calcium transport measurements. $\mathrm{Ca}^{2+}$ uptake into mitochondria was followed by measuring the decrease of $\mathrm{Ca}^{2+}$ concentration in the incubation medium with a small $\mathrm{Ca}^{2+}$-selective electrode constructed using calcium-selective membranes (Calcium Ionophore IV-membrane A; Fluka, Buchs, Switzerland).

Mitochondrial swelling. $\mathrm{Ca}^{2+}$-induced large amplitude mitochondrial swelling, reflecting $\mathrm{mPT}$ opening, was followed by measuring changes in the light absorbance at $540 \mathrm{~nm}\left(\Delta \mathrm{A}_{540}\right)$ of the mitochondrial suspension in standard incubation medium at room temperature using a Beckman DU7500 spectrophotometer. The mitochondrial suspension was stirred after each addition. Alternatively, mitochondrial swelling was measured simultaneously with external $\mathrm{TPP}^{+}$measurements at $30^{\circ} \mathrm{C}$ under continuous stirring. For the dual measurements, a $0.3 \mathrm{ml}$ thermostated chamber was equipped with a $\mathrm{TPP}^{+}$-sensitive electrode, a light source passing wavelengths above $540 \mathrm{~nm}$ with a peak at $650 \mathrm{~nm}$ and a light detector. All data traces shown are representative of at least three replicates.

Respiration measurements. CNS mitochondria were incubated in standard incubation medium at $30^{\circ} \mathrm{C}$ under continuous stirring. The $2 \mathrm{ml}$ incubation chamber was equipped with a Clark-type oxygen electrode and a tightly closed lid. The slope of the $\mathrm{O}_{2}$ electrode trace corresponds to the respiration rate. Respiration rates were compared in a one-way ANOVA followed by Bonferroni's multiple comparison $t$ tests.

A diagram of the metabolic pathways referred to in this paper is included in the summary scheme of Figure 9.

Fluorescence microscopy. Cultured hippocampal neurons were loaded with $4 \mu \mathrm{M}$ fura-2FF AM (Teflabs, Austin, TX) for 45 min alone or in combination with $0.5 \mu \mathrm{g} / \mathrm{ml}$ rhodamine 123 (R123; Molecular Probes, Eugene, OR) for the last $15 \mathrm{~min}$ in the growing medium. In some experiments, loading of individual neurons was accomplished by $60 \mathrm{sec}$ of dialysis through a patch pipette in whole-cell configuration containing (in mM): $0.2 \mathrm{~K}$-fura-2FF (Teflabs), $115 \mathrm{~K}$ gluconate, $20 \mathrm{KCl}, 10 \mathrm{Na}-$ HEPES, and $5 \mathrm{MgATP}, \mathrm{pH}$ 7.1. The cultures were mounted on the stage of a Nikon Diaphot microscope in recording solution containing (in $\mathrm{mM}$ ) $139 \mathrm{NaCl}, 3 \mathrm{KCl}, 10 \mathrm{NaHEPES}, 1.8 \mathrm{CaCl}_{2}, 0.8 \mathrm{MgCl}_{2}, 5$ glucose, 15

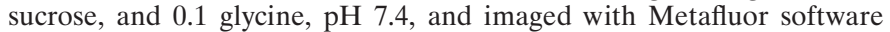
(Universal Imaging, West Chester, PA) as previously described (Dubinsky and Levi, 1998). Cells were illuminated alternately with $340 \pm 15$ and $380 \pm 15 \mathrm{~nm}$ light for fura- $2 \mathrm{FF}$ and $490 \pm 15 \mathrm{~nm}$ light for R123, all attenuated with a quartz $10 \%$ transmittance neutral density filter. Emitted fluorescence was captured with an Olympus $100 \times 1.3$ NA oil objective through a $505 \mathrm{~nm}$ dichroic mirror, $535 \pm 25 \mathrm{~nm}$ emission filter, and Photometrics PXL cooled CCD camera. Average regional intensities over neuronal cytoplasm were obtained after subtraction of background images from unpopulated areas of the culture dish. For R123 experiments, the medium perfusing the cells $(1 \mathrm{ml} / \mathrm{min})$ contained $0.5 \mu \mathrm{g} / \mathrm{ml}$ R123.

Fura-2FF calibrations were performed either on the same cells that had previously been challenged with glutamate or on cells in a sister dish from the same plating. In all cases, neurons were exposed to $10 \mu \mathrm{M}$ ionomycin in recording solution with $10 \mathrm{mM} \mathrm{CaCl}_{2}$, followed by rinsing in the recording solution with no added $\mathrm{Ca}^{2+}$ and $15 \mathrm{~mm}$ EGTA. Measurements of $\mathrm{K}_{\mathrm{D}} * \beta$ equal to $155 \mu \mathrm{M}$ were obtained from the slope of a plot of $\log \left[\left(R-R_{\min }\right) /\left(R_{\max }-R\right)\right]$ versus $\log \left[\mathrm{Ca}^{2+}\right]$ in standard $\mathrm{Ca}^{2+}$-containing solutions (Molecular Probes; Calcium Calibration Buffer kit 3), according to the kit directions. A comparable value of $\mathrm{K}_{\mathrm{D}}$ * $\beta(149 \mu \mathrm{M})$ was obtained with standard solutions prepared in the laboratory. For neurons individually exposed to ionomycin, cytoplasmic $\left[\mathrm{Ca}^{2+}\right]\left(\left[\mathrm{Ca}^{2+}\right]_{\mathrm{i}}\right)$ were obtained from the equation, $\log \left[\mathrm{Ca}^{2+}\right]_{\mathrm{i}}=\log$ $\left[\mathrm{K}_{\mathrm{D}} * \beta\right]+\log \left[\left(R-R_{\min }\right) /\left(R_{\max }-R\right)\right]$ (Grynkiewicz et al., 1985), using $R_{\max }$ and $R_{\min }$ determined for each cell and $\mathrm{K}_{\mathrm{D}} * \beta=155 \mu \mathrm{M}$. Ranges of individual values for $R_{\max }$ and $R_{\min }$ were 2.6-6.1 and 0.307-0.461, respectively. Individual values of $\beta$ were not reliable in cells previously exposed to glutamate because small amounts of dye loss were observed in the presence of DMSO as the ionomycin solvent. Thus accurate determinations of F380-infinity, F380-zero, and hence $\beta$ were only possible in calibrations performed on sister dishes. When dye loss occurred, $R_{\min }$ was usually greater than the initial ratio levels by up to $10 \%$. When this occurred, initial ratios were used for $R_{\min }$. For fura-2FF AM-loaded cells not exposed to ionomycin, determinations of $\left[\mathrm{Ca}^{2+}\right]_{\mathrm{i}}$ were calculated from $\left[\mathrm{Ca}^{2+}\right]_{\mathrm{i}}=\mathrm{K}_{\mathrm{D}} * \beta *\left(R-R_{\min }\right) /\left(R_{\max }-R\right)$ (Grynkiewicz et al., 1985) using an $R_{\max }, R_{\min }$, and $\beta$ of 3.1,0.2, and 5.5, respectively, and a $\mathrm{K}_{\mathrm{D}}$ of $35 \mu \mathrm{M}$ (Golovina and Blaustein, 1997). Approximately 7\% of the R123 signal was observed to bleed through into the fura-2FF wavelengths, preventing accurate calibration of the fura-2FF signal in the cultures loaded with both dyes.

\section{RESULTS}

\section{Mitochondrial responses to $\mathrm{Ca}^{2+}$ depended on oxidative substrate}

By varying oxidative substrates, the proton-pumping capacity and redox state of the electron-transporting chain can be modulated. A decrease of the proton-pumping activity accompanying suppression of electron transport may facilitate detection of proton leakage that would normally be compensated for by active proton extrusion. Using this approach, two distinct mitochondrial responses to calcium were obtained that depended on the substrates available to the isolated CNS mitochondria. This differential response could be observed with $\mathrm{TPP}^{+}$or $\mathrm{Ca}^{2+}$ electrodes or in absorbance assays. In the presence of succinate plus glutamate, $\mathrm{Ca}^{2+}$ transiently depolarized CNS mitochondria. After the rapid recovery of $\Delta \psi$, a slow secondary depolarization was observed (Fig. 1A). A similar response to $\mathrm{Ca}^{2+}$ was obtained in the presence of $3 \mathrm{~mm}$ succinate plus $1 \mu \mathrm{M}$ rotenone or with $3 \mathrm{~mm}$ pyruvate plus $3 \mathrm{~mm}$ malate (data not shown). In contrast, in the presence of $3 \mathrm{~mm}$ succinate, $\mathrm{Ca}^{2+}$ induced a sustained depolarization (Fig. $1 A$ ). $\mathrm{Ca}^{2+}$ also induced a sustained depolarization when submillimolar quantities of succinate plus glutamate or the 

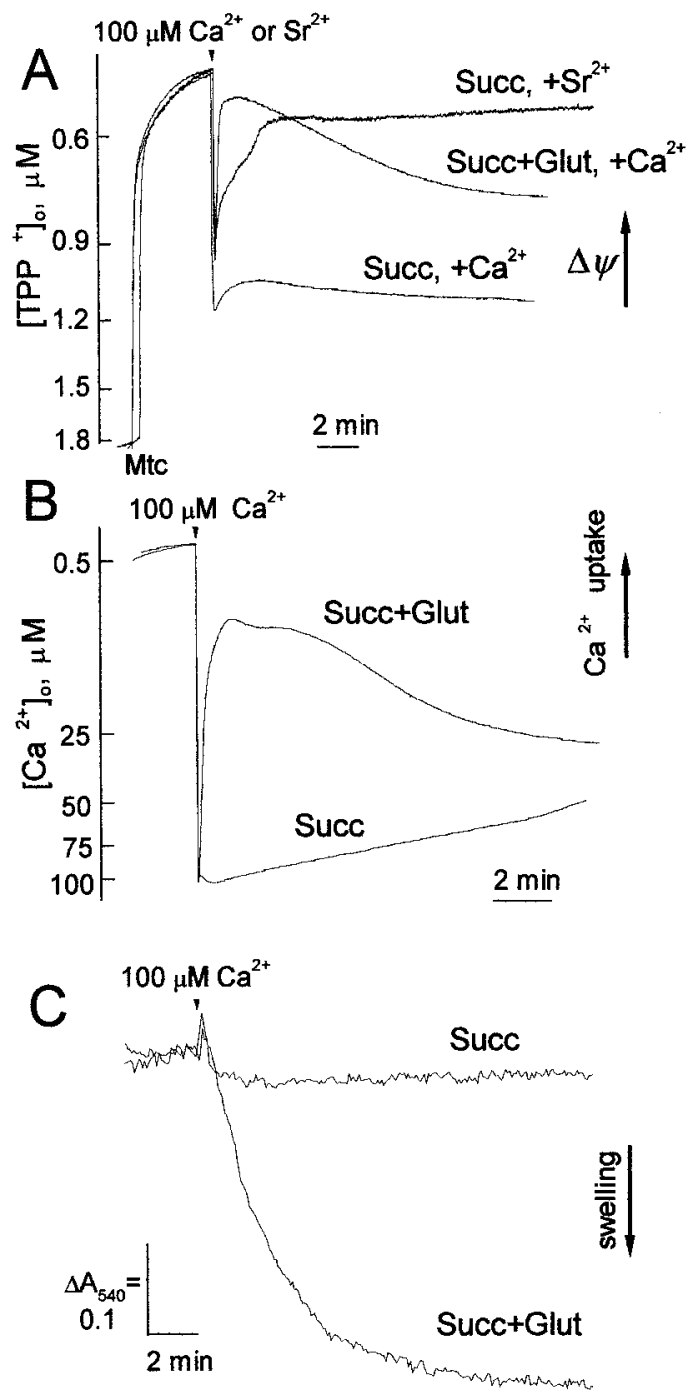

Figure 1. Dependence of the mitochondrial responses to $\mathrm{Ca}^{2+}$ on various oxidative substrates. $A$, TPP ${ }^{+}$measurements of mitochondrial $\Delta \psi$ in response to $\mathrm{Ca}^{2+}$ or $\mathrm{Sr}^{2+}$ in isolated CNS mitochondria respiring on 3 mM succinate and to $\mathrm{Ca}^{2+}$ in mitochondria respiring on $3 \mathrm{~mm}$ succinate plus $3 \mathrm{~mm}$ glutamate. $B$, $\mathrm{Ca}^{2+}$ electrode measurements of $\mathrm{Ca}^{2+}$ uptake and retention initiated by a $100 \mu \mathrm{M} \mathrm{Ca}^{2+}$ challenge. Responses vary depending on the indicated oxidative substrates present initially. $C, \mathrm{Ab}-$ sorbance measurements of purified CNS mitochondria reveal the amplitude of swelling depended on oxidative substrate as well. Mtc indicates addition of mitochondria.

$\mathrm{NADH}$-linked substrates were used (data not shown). Addition of $\mathrm{Sr}^{2+}$, which can also be transported into mitochondria by the $\mathrm{Ca}^{2+}$ uniporter (Gunter and Pfeiffer, 1990), did not cause the sustained depolarization, indicating the response was specific for $\mathrm{Ca}^{2+}$. After a $\mathrm{Sr}^{2+}$-induced transient depolarization, mitochondria spontaneously repolarized and maintained a high $\Delta \psi($ Fig. $1 A)$.

$\mathrm{Ca}^{2+}$ uptake by isolated CNS mitochondria varied substantially depending on the oxidative substrate. In the presence of succinate plus glutamate, mitochondria rapidly accumulated $\mathrm{Ca}^{2+}$ (Fig. $1 B$ ). This phase was followed by slow spontaneous $\mathrm{Ca}^{2+}$ release. $\mathrm{Ca}^{2+}$ accumulation was comparable in mitochondria respiring on succinate plus rotenone or pyruvate plus malate. In the presence of $3 \mathrm{~mm}$ succinate, the rate of $\mathrm{Ca}^{2+}$ uptake was greatly suppressed. Inhibition of $\mathrm{Ca}^{2+}$ uptake accompanied the strong, sustained depolarization observed in these conditions

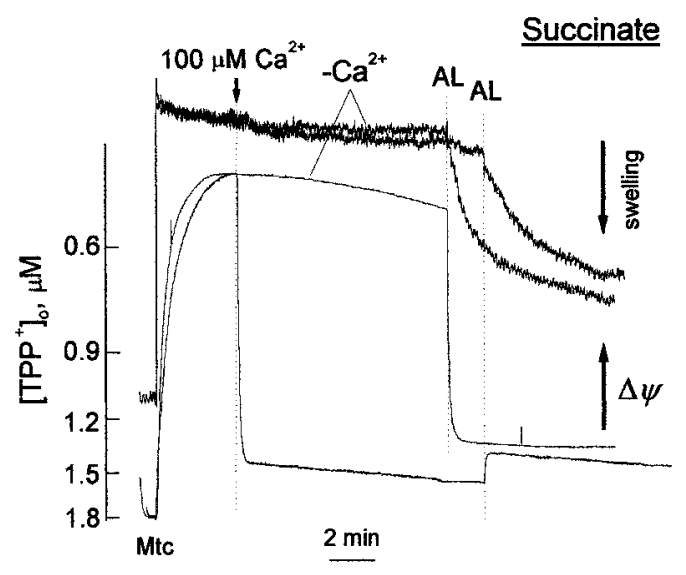

Figure 2. Simultaneous recordings of external $\mathrm{TPP}^{+}$and light absorbance $\left(\Delta \mathrm{A}_{650}\right)$ in purified brain mitochondria demonstrated that $100 \mu \mathrm{M}$ $\mathrm{Ca}^{2+}$ caused depolarization without appreciable swelling in the presence of $3 \mathrm{~mm}$ succinate. $\mathrm{Ca}^{2+}$ was not added to the control trace $\left(-\mathrm{Ca}^{2+}\right)$. A $20 \mu \mathrm{M}$ concentration of alamethicin $(A L)$ produced maximal swelling independent of calcium.

(Fig. 1A), suggesting that depolarization itself might prevent $\mathrm{Ca}^{2+}$ uptake and subsequent mitochondrial swelling.

Addition of $100 \mu \mathrm{M} \mathrm{Ca}^{2+}$ to purified CNS mitochondria respiring on succinate plus glutamate induced maximal mitochondrial swelling (Fig. 1C). Swelling was extremely limited in $3 \mathrm{~mm}$ succinate, comprising $7.2 \pm 1.4 \%$ (mean $\pm \mathrm{SEM} ; n=3$ ) of the maximal response after $15 \mathrm{~min}$. In comparable experiments, exposure to $300 \mu \mathrm{M} \mathrm{Ca}^{2+}$ caused swelling in mitochondria respiring on succinate plus glutamate, pyruvate plus malate, or succinate plus rotenone. In mitochondria respiring on $3 \mathrm{~mm}$ succinate alone the amplitude of swelling was greatly diminished. Omission of $\mathrm{Mg}^{2+}$ accelerated mitochondrial swelling, but did not qualitatively change mitochondrial responses. In succinate plus glutamate, the secondary slow depolarization, slow release of $\mathrm{Ca}^{2+}$, and swelling represent responses expected for activation of the $\mathrm{mPT}$ pore. The sustained depolarization could represent opening of a substrate of the mPT pore, insufficient to produce large amplitude swelling. Alternatively, the minimal swelling accompanying depolarization in $3 \mathrm{~mm}$ succinate suggested other permeabilities might be activated in these circumstances.

To confirm the results obtained separately with the $\mathrm{TPP}^{+}$ electrode and in the absorbance assay, both parameters, $\Delta \psi$ and mitochondrial swelling, were measured simultaneously in the same preparation (Fig. 2). The amplitude of swelling observed in response to $100 \mu \mathrm{M} \mathrm{Ca}^{2+}$ with $3 \mathrm{~mm}$ succinate was very small, despite strong depolarization. The purified mitochondria that have undergone gradient centrifugation appear to be more sensitive to $\mathrm{Ca}^{2+}$ and depolarize more than unpurified CNS mitochondria. Alamethicin, an antibiotic that forms large conductance channels (Vodyanoy et al., 1992), was added to demonstrate maximal swelling at the end of each trace.

The magnitude of the sustained $\mathrm{Ca}^{2+}$-induced depolarization obtained in the presence of $3 \mathrm{~mm}$ succinate depended on the concentration of $\mathrm{Ca}^{2+}$ and the presence of external $\mathrm{Mg}^{2+}$, but not on the concentration of $\mathrm{P}_{\mathrm{i}}$. Increasing doses of $\mathrm{Ca}^{2+}(25-300$ $\mu \mathrm{M})$ produced greater amplitudes of sustained depolarization (data not shown). Omission of $\mathrm{Mg}^{2+}$ from the medium further increased the $\mathrm{Ca}^{2+}$-induced depolarization. The depolarization was completely reversed after chelation of $\mathrm{Ca}^{2+}$ by $0.5 \mathrm{~mm}$ EGTA. $\mathrm{P}_{\mathrm{i}}$ equilibrates $\mathrm{pH}$ across the mitochondrial membrane 

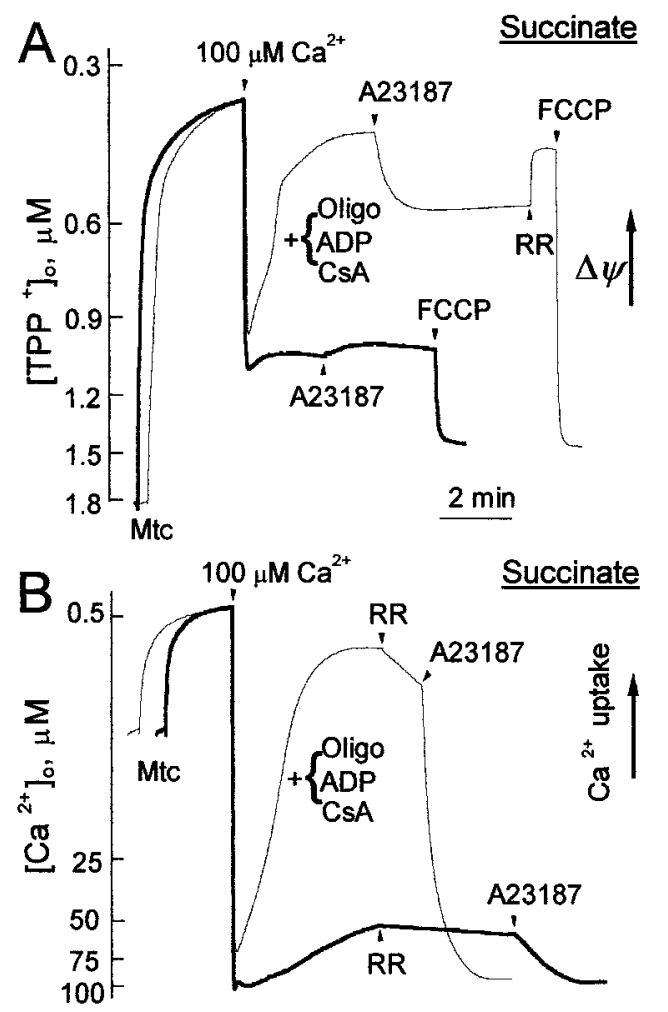

$\underline{2 \min }$

Figure 3. Depolarization associated with $\mathrm{Ca}^{2+}$ cycling was observed in polarized mitochondria with large $\mathrm{Ca}^{2+}$ fluxes but not in depolarized mitochondria with limited $\mathrm{Ca}^{2+}$ fluxes. $A$, TPP ${ }^{+}$electrode measurements monitored changes in $\Delta \psi$ associated with $\mathrm{Ca}^{2+}$ cycling produced by $2 \mu \mathrm{M}$ A23187. $B, \mathrm{Ca}^{2+}$ electrode measurements reflect rates of $\mathrm{Ca}^{2+}$ influx and efflux under comparable conditions. Mitochondria were respiring on $3 \mathrm{~mm}$ succinate in the presence (thin lines) or absence (thick lines) of $100 \mu \mathrm{M}$ ADP, $1 \mu \mathrm{M}$ oligomycin (Oligo) and $1 \mu \mathrm{M}$ CsA. Other additions: $1 \mu \mathrm{M}$ ruthenium red $(R R)$ and $1 \mu \mathrm{M}$ FCCP. These same concentrations were used in subsequent figures.

decreasing the $\Delta \mathrm{pH}$ component of $\Delta \mu_{\mathrm{H}+}$, favoring an increase of $\Delta \psi$. Whereas increasing concentrations of $\mathrm{P}_{\mathrm{i}}$ increased initial values of $\Delta \psi$, saturating at 3-6 mM, the $\mathrm{Ca}^{2+}$-induced depolarization was insensitive to $\mathrm{P}_{\mathrm{i}}$ over a range of $0-20 \mathrm{~mm}$ (data not shown).

\section{Possible mechanisms for the sustained $\mathrm{Ca}^{2+}$-induced depolarization}

In $3 \mathrm{~mm}$ succinate, the $\mathrm{Ca}^{2+}$-activated sustained depolarization with minimal swelling may be attributable to several causes. These include (1) activation of $\mathrm{Ca}^{2+}$ cycling across the inner mitochondrial membrane, (2) partial inhibition of oxidation and therefore insufficient proton pumping activity to compensate dissipation of $\Delta \psi$, and/or (3) increased $\mathrm{H}^{+}$permeability of the inner mitochondrial membrane via the $\mathrm{mPT}$ or another permeability pathway.

To test the $\mathrm{Ca}^{2+}$ cycling hypothesis, we compared $\mathrm{Ca}^{2+}$ fluxes and corresponding depolarizations in different conditions. The rates of $\mathrm{Ca}^{2+}$ influx and efflux should determine the overall extent of $\mathrm{Ca}^{2+}$ cycling. In mitochondria pretreated with ADP, oligomycin, and CsA to inhibit the pathway responsible for the $\mathrm{Ca}^{2+}$-activated sustained depolarization, a $100 \mu \mathrm{M} \mathrm{Ca}{ }^{2+}$ application was accumulated rapidly (Fig. $3 B$, thin line), accompanied by only a transient mitochondrial depolarization (Fig. $3 A$, thin
Table 1. Mitochondrial oxygen consumption associated with different experimental conditions

\begin{tabular}{lcc} 
& \multicolumn{2}{l}{ Substrate } \\
\cline { 2 - 3 } Condition & $3 \mathrm{~mm}$ succinate & $\begin{array}{c}3 \mathrm{~mm} \text { succinate }+ \\
3 \mathrm{~mm} \text { glutamate }\end{array}$ \\
\hline State 4, without ADP & $8.9 \pm 0.5$ & $9.8 \pm 0.4$ \\
State 3, 100 $\mu \mathrm{M}$ ADP & $24.3 \pm 3.2$ & $38.6 \pm 2.6^{*}$ \\
Maximal, $1 \mu \mathrm{M}$ FCCP & $23.2 \pm 2.6$ & $93.3 \pm 7.6^{* *}$
\end{tabular}

Data are mean \pm SEM, in units of nanomoles of $\mathrm{O}_{2} / \mathrm{min}^{-1} / \mathrm{mg}_{\text {protein }}{ }^{-1}$. Four replicates are included in each category.

${ }^{*} p<0.05$ compared to succinate alone.

${ }^{* *} p<0.001$ compared to succinate alone.

line). To maximally increase $\mathrm{Ca}^{2+}$ efflux, $2 \mu \mathrm{M}$ A23187, an artificial $\mathrm{Ca}^{2+}-\mathrm{H}^{+}$exchanger (Reed and Lardy, 1972), was applied. The ionophore provided a pathway for maximal $\mathrm{Ca}^{2+}$ efflux (Fig. $3 B$, thin line) promoting optimal conditions for maximal $\mathrm{Ca}^{2+}$ cycling and $\Delta \psi$ dissipation. The associated mitochondrial depolarization was detectable but amounted to $\sim 10 \mathrm{mV}$ (Fig. $3 A$, thin line). Inhibition of the $\mathrm{Ca}^{2+}$ uniporter with ruthenium red (RR) interrupted the cycling and restored $\Delta \psi$ (Fig. 3A). Under these optimal conditions for $\mathrm{Ca}^{2+}$ cycling, the depolarization was only minor. In contrast, when ADP, oligomycin, and CsA were omitted from the medium, $\mathrm{Ca}^{2+}$ produced a sustained depolarization (Fig. 3A, thick line) with restricted $\mathrm{Ca}^{2+}$ uptake (Fig. 3B, thick line). Substantial suppression of $\mathrm{Ca}^{2+}$ uptake and correspondingly low $\mathrm{Ca}^{2+}$ load made activation of $\mathrm{Ca}^{2+}$ cycling unlikely. Addition of A23187, again to provide an efflux pathway creating optimal conditions for $\mathrm{Ca}^{2+}$ cycling, did not produce the expected depolarization (Fig. $3 A$, thick line). A minor repolarization was observed. Suppression of $\mathrm{Ca}^{2+}$ influx by RR unmasked only a minor amount of $\mathrm{Ca}^{2+}$ efflux compared to that activated by A23187 (Fig. 3B, thick line). Thus, only minor $\mathrm{Ca}^{2+}$ cycling was observed in the more depolarized mitochondria, whereas robust $\mathrm{Ca}^{2+}$ cycling was detected only in relatively polarized mitochondria. This inverse correlation between $\mathrm{Ca}^{2+}$ fluxes and the depolarization level indicated that $\mathrm{Ca}^{2+}$ cycling did not appear to contribute substantially to the sustained depolarization.

To determine if restrictions in respiratory capacity contributed to the observed responses, $\mathrm{O}_{2}$ consumption was measured (Table 1). In the presence of succinate plus glutamate, CNS mitochondria were able to maintain $\Delta \psi$ and to accumulate $\mathrm{Ca}^{2+}$ more effectively than mitochondria respiring on a limited amount of succinate alone (Fig. 1). Correspondingly, CNS mitochondria had a higher maximal oxidative capacity in the presence of succinate plus glutamate (Table 1). The rate of respiration without ADP (state 4) was the same in both conditions. With ADP, state 3 respiration was slightly higher in the combined substrates. However, the rate of uncoupled respiration was fourfold higher with the combined substrates. Comparable results were obtained with succinate plus rotenone. These data suggest that, in the presence of $3 \mathrm{~mm}$ succinate, respiratory capacity may have been limited by oxaloacetate accumulation and subsequent inhibition of succinate dehydrogenase (SDH; Oestreicher et al., 1969; Papa et al., 1969; Wojtczak, 1969). Such inhibition of electron transport could be partially responsible for the failure of mitochondria to restore $\Delta \psi$ after a $\mathrm{Ca}^{2+}$-induced sustained depolarization.

Simultaneous measurements of oxygen consumption and $\Delta \psi$ were performed to investigate this possibility further. In $3 \mathrm{~mm}$ succinate, the $\mathrm{Ca}^{2+}$-induced sustained depolarization was not 


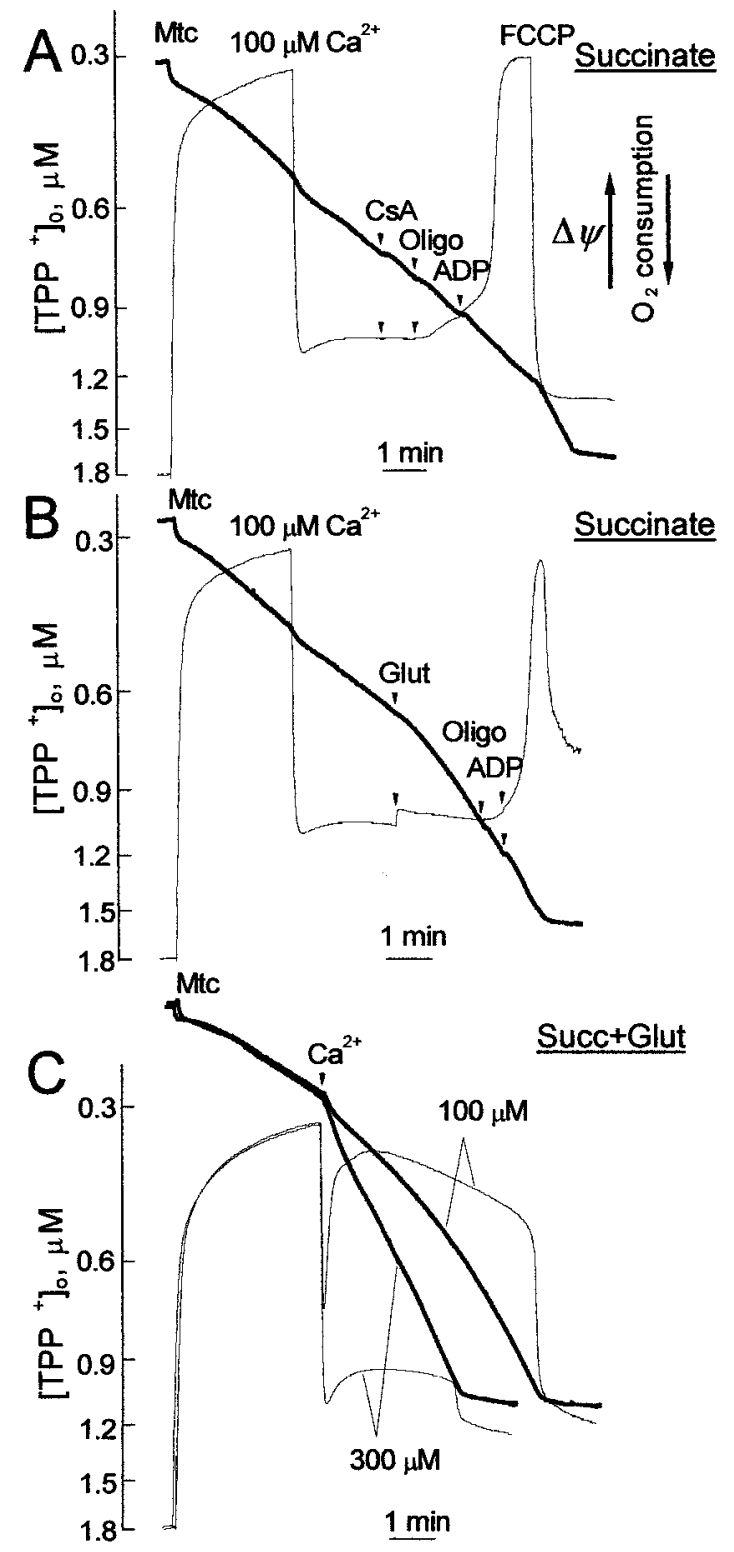

Figure 4. Simultaneous measurement of $\mathrm{TPP}^{+}$accumulation $(\Delta \psi$, thin line) and $\mathrm{O}_{2}$ consumption (thick line) in mitochondria respiring on $3 \mathrm{~mm}$ succinate $(A, B)$ or succinate plus glutamate $(C)$. $A$, Respiratory increases did not accompany $\mathrm{Ca}^{2+}$-induced depolarization or repolarization by CsA, oligomycin, and ADP. FCCP maximally activated respiration. $B$, Respiratory increases were observed after sequential addition of $3 \mathrm{~mm}$ glutamate and ADP. Consumption of all available $\mathrm{O}_{2}$ resulted in mitochondrial depolarization. $C$, Respiratory increases were observed in response to $\mathrm{Ca}^{2+}$ in mitochondria in the presence of succinate plus glutamate.

accompanied by sustained activation of respiration (Fig. 4A,B). After $\mathrm{Ca}^{2+}$ induced depolarization, a combination of CsA and ADP, inhibitors of the mPT (Hunter and Haworth, 1979; Fournier et al., 1987; Crompton et al., 1988; Broekemeier et al., 1989; Novgorodov et al., 1992; Zoratti and Szabo, 1995), and oligomycin, to prevent ADP phosphorylation, completely repolarized mitochondria (Fig. 4A). Oligomycin plus ADP also repolarized mitochondria in the absence of CsA (Fig. 4B). CsA alone repolarized mitochondria depolarized by $50 \mu \mathrm{M} \mathrm{Ca}^{2+}$ (data not shown). The rate of respiration increased only after carbonyl cyanide- $p$-trifluoromethoxyphenyl hydrazone (FCCP) produced complete depolarization. ADP in the presence of oligomycin did not reactivate $\mathrm{SDH}$ and respiration. With the substrate conditions limiting respiratory capacity, respiration and proton extrusion were only activated transiently, largely remaining constant, unmasking the presence of $\mathrm{Ca}^{2+}$-activated proton influx. The ADPinduced repolarization was presumably caused by inhibition of the permeability induced by $\mathrm{Ca}^{2+}$.

Correspondingly, $3 \mathrm{~mm}$ glutamate application during the $\mathrm{Ca}^{2+}$-induced depolarization increased respiration without restoring $\Delta \psi$ (Fig. $4 B$ ). In this case, glutamate activated respiration apparently because of removal of oxaloacetate in the transaminase reaction and reactivation of SDH (Oestreicher et al., 1969). However, despite the SDH reactivation, $\Delta \psi$ remained low until oligomycin plus ADP were applied. Reactivation of SDH alone could not repolarize mitochondria. The initial presence of glutamate fostered an environment with sufficient oxidative capacity to prevent observation of a $\mathrm{Ca}^{2+}$-induced sustained depolarization. However, glutamate addition after onset of the sustained depolarization was insufficient to close this pathway. Thus, the sustained depolarization did not result from a $\mathrm{Ca}^{2+}$-induced inhibition of respiration. It may be attributable to a $\mathrm{Ca}^{2+}$-induced permeability increase observable under conditions of restricted respiratory capacity.

$\mathrm{Ca}^{2+}$-activated respiration could be demonstrated in CNS mitochondria respiring on succinate plus glutamate (Fig. $4 C$ ). In response to $100 \mu \mathrm{M} \mathrm{Ca}{ }^{2+}$, a short initial burst of respiratory activity followed by a secondary slow gradual activation of respiration was observed. A $100 \mu \mathrm{M}$ concentration of $\mathrm{Ca}^{2+}$ also evoked a transient depolarization followed by a secondary decline of $\Delta \psi, \mathrm{Ca}^{2+}$ accumulation followed by slow spontaneous $\mathrm{Ca}^{2+}$ release, and large amplitude swelling (Fig. 1). Induction of the $\mathrm{mPT}$ pore might cause the secondary activation of respiration and depolarization, spontaneous $\mathrm{Ca}^{2+}$ release, and mitochondrial swelling. Slow development of these reactions might reflect the slow propagation of mPT induction through the mitochondrial population (Beatrice et al., 1982; Bernardi, 1992; Zoratti and Szabo, 1995). Mitochondria responded to a larger, $300 \mu \mathrm{M}$ $\mathrm{Ca}^{2+}$ pulse with an immediate sustained activation of respiration accompanied by a sustained depolarization (Fig. 4C) and slowed $\mathrm{Ca}^{2+}$ uptake (Fig. $7 C$ ). A $300 \mu \mathrm{M}$ concentration of $\mathrm{Ca}^{2+}$ produced rapid mitochondrial swelling in parallel experiments (data not shown), complicating the interpretation of the $\mathrm{TPP}^{+}$measurements (Gunter and Pfeiffer, 1990; Bernardi, 1992).

Despite the restricted respiratory capacity in $3 \mathrm{~mm}$ succinate, once CsA, oligomycin, and ADP repolarized CNS mitochondria, their ability to sequester $\mathrm{Ca}^{2+}$ was restored (Fig. 5). Subsequent application of a second $\mathrm{Ca}^{2+}$ challenge resulted in $\mathrm{Ca}^{2+}$ uptake (Fig. $5 B$ ) and only a transient depolarization (Fig. $5 A$ ). Thus, by closing the $\mathrm{Ca}^{2+}$-induced permeability pathway, ADP restored $\mathrm{Ca}^{2+}$ accumulation in CNS mitochondria respiring on $3 \mathrm{~mm}$ succinate. When ADP and oligomycin were present initially, the $\mathrm{Ca}^{2+}$-induced sustained depolarization was prevented (Fig. 6A). In contrast, CsA, an inhibitor of the mPT (Fournier et al., 1987; Crompton et al., 1988; Broekemeier et al., 1989; Zoratti and Szabo, 1995), neither prevented the sustained depolarization of mitochondria challenged by $100 \mu \mathrm{M} \mathrm{Ca}^{2+}$ (Fig. 6 $A$ ) nor repolarized mitochondria after this $\mathrm{Ca}^{2+}$ challenge (Figs. $4 A, 5 A$ ). ADP plus oligomycin also prevented the sustained depolarization in the presence of succinate plus glutamate when CNS mitochondria were challenged by $300 \mu \mathrm{M} \mathrm{Ca}{ }^{2+}$ (Fig. 6B,C). Under these conditions, $\mathrm{Ca}^{2+}$ caused a transient depolarization, repolarization accompanied by $\mathrm{Ca}^{2+}$ uptake, and subsequent slow $\mathrm{Ca}^{2+}$ 

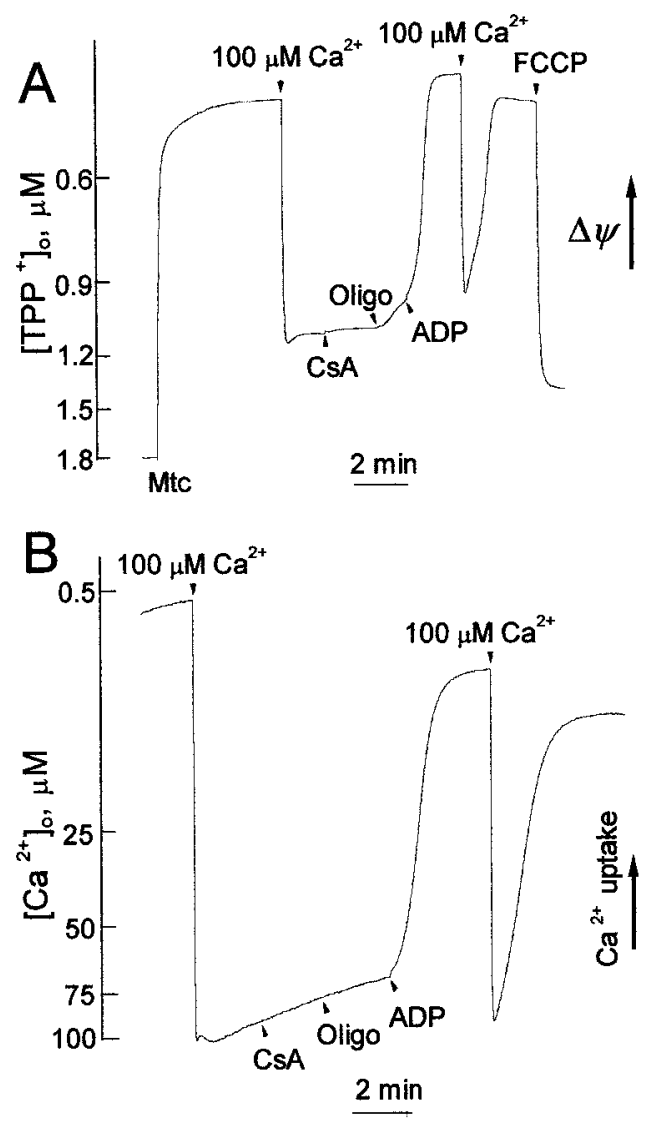

Figure 5. Restoration of mitochondrial function by CsA and ADP in the presence of $3 \mathrm{~mm}$ succinate. Mitochondria were challenged by $100 \mu \mathrm{M}$ $\mathrm{Ca}^{2+}$. Repolarization of CNS mitochondria $(A)$ and restoration of $\mathrm{Ca}^{2+}$ uptake $(B)$ were observed after addition of CsA and oligomycin plus ADP. After addition of the combination of agents, mitochondria spontaneously repolarized and accumulated $\mathrm{Ca}^{2+}$ in response to a second pulse of $100 \mu \mathrm{M} \mathrm{Ca}^{2+}$.

release and decline in $\Delta \psi$. This pattern of responses is characteristic of induction of the mPT pore (Fig. 1). The improved ability of CNS mitochondria to effectively sequester $\mathrm{Ca}^{2+}$ was presumably attributable to maintenance of a relatively high $\Delta \psi$. When $\mathrm{CsA}$, ADP, and oligomycin were all present before $\mathrm{Ca}^{2+}$ addition, the secondary gradual depolarization and $\mathrm{Ca}^{2+}$ release were slowed (Fig. 6C).

The ability of ADP to repolarize mitochondria during a sustained depolarization could be attributable to its interaction with the adenine nucleotide translocator (ANT), a putative candidate for the conductive pathway of the mPT pore (LeQuoc and LeQuoc, 1988; Halestrap and Davidson, 1990; Brustovetsky and Klingenberg, 1996; Ruck et al., 1998). To test for possible ANT involvement in the observed increase of membrane permeability, the ANT inhibitor bongkrekic acid (BKA), was used to suppress the mPT (Klingenberg, 1985; Zoratti and Szabo, 1995). In contrast to ADP, $5 \mu \mathrm{M}$ BKA neither prevented depolarization nor repolarized mitochondria (data not shown). A $5 \mu \mathrm{M}$ concentration of carboxyatractylate (CAT), another inhibitor of the ANT that prevents its interaction with nucleotides in both high- and low-affinity binding sites (Klingenberg, 1985), added before (data not shown) or after $\mathrm{Ca}^{2+}$, did not abolish the ADP effect (Fig. $7 A$ ). This concentration of CAT was sufficient to completely prevent ADP-induced stimulation of respiration and depolarization caused by activation of oxidative phosphorylation (Fig.
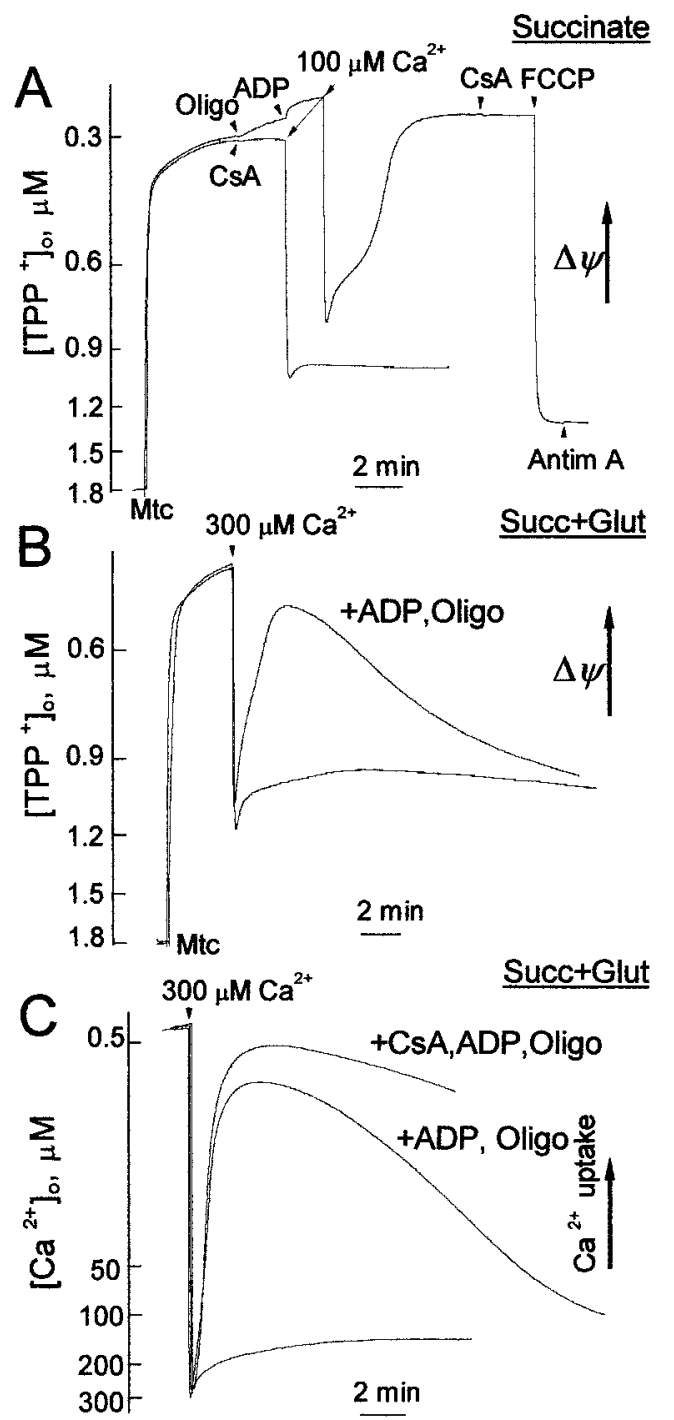

Figure 6. The initial presence of ADP plus oligomycin, but not CsA, prevented the $\mathrm{Ca}^{2+}$-induced sustained depolarization in mitochondria respiring on $3 \mathrm{~mm}$ succinate $(A)$ or $3 \mathrm{~mm}$ succinate plus $3 \mathrm{~mm}$ glutamate $(B)$. Other addition: $1 \mu \mathrm{M}$ antimycin A $($ Antim $A) . C, \mathrm{Ca}^{2+}$ uptake was greatly improved when pretreated with ADP plus oligomycin alone or ADP, oligomycin, and CsA.

$7 B, C$ ), indicating complete inhibition of the ANT. Applied together, CAT and BKA (5 $\mu \mathrm{M}$ each) were unable to alter the ability of ADP to repolarize mitochondria. ADP repolarized mitochondria under all conditions, irrespective of the degree of mitochondrial depolarization. A $100 \mu \mathrm{M}$ concentration of diadenosine-pentaphosphate, an inhibitor of adenylate kinase, did not influence the effect of ADP (data not shown; Novgorodov et al., 1991). A $100 \mu \mathrm{M}$ concentration of ATP as well as its nonhydrolyzable derivative, $\mathrm{ATP} \gamma \mathrm{S}$, also restored $\Delta \psi$ (data not shown). AMP as well as guanine and uridine nucleotides were ineffective at concentrations up to $100 \mu \mathrm{M}$.

\section{In situ behavior consistent with a $\mathrm{Ca}^{2+}$-activated, sustained mitochondrial depolarization}

To determine if elevated cytosolic $\mathrm{Ca}^{2+}$ depolarized mitochondria in a manner consistent with activation of the pathway identified in isolated mitochondria, hippocampal neurons were loaded with both fura-2FF AM and R123 for simultaneous monitoring of 

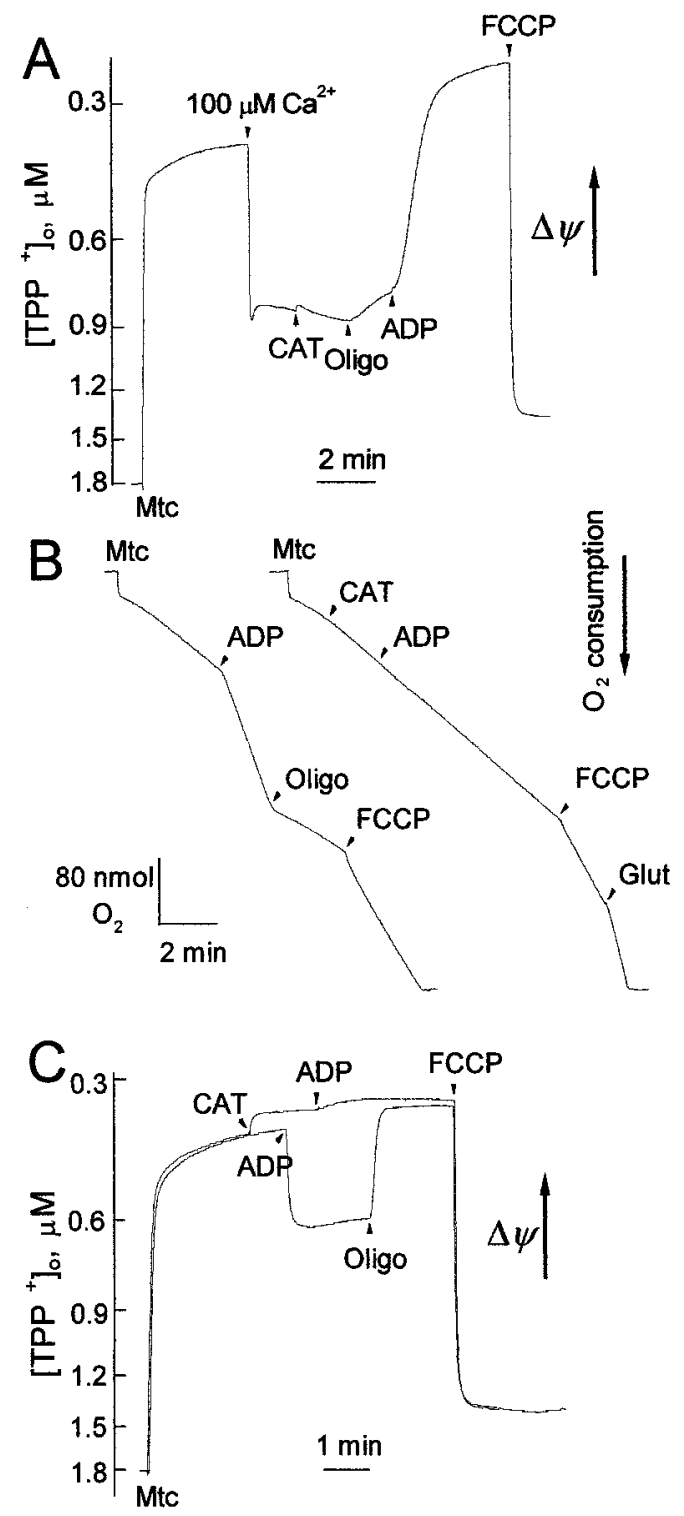

Figure 7. Lack of effect of CAT on ADP repolarization after sustained mitochondrial depolarization in the presence of $3 \mathrm{~mm}$ succinate. $A$, Carboxyatractylate $(5 \mu \mathrm{M}$ CAT) did not prevent $100 \mu \mathrm{M}$ ADP-induced repolarization of CNS mitochondria after $100 \mu \mathrm{M} \mathrm{Ca}{ }^{2+}$-induced depolarization. $B$, Mitochondrial respiration was not stimulated by ADP in the presence of CAT. In the left trace, control mitochondria increased $\mathrm{O}_{2}$ consumption after addition of ADP. This was inhibited by oligomycin. In the right trace, $5 \mu \mathrm{M}$ CAT addition prevented any changes in $\mathrm{O}_{2}$ consumption by ADP. In both traces, FCCP was added to maximally stimulate respiration. The addition of $3 \mathrm{~mm}$ glutamate as additional substrate increased the maximal rate of respiration, illustrating the data presented in Table 1. $C$, $\mathrm{TPP}^{+}$measurements of $\Delta \psi$ under conditions comparable to $B$ demonstrate that CAT prevented mitochondrial depolarization associated with ADP-stimulated respiratory increases.

$\Delta \psi$ and $\left[\mathrm{Ca}^{2+}\right]_{\mathrm{i}}$. Only a minor mitochondrial depolarization was observed during high potassium depolarization (Fig. 8B). R123 intensity increased in response to glutamate, reflecting unquenching of the dye as mitochondria depolarized (Duchen, 1992). The time course of mitochondrial potential recovery varied considerably among cells, encompassing almost full repolarization, repolarization to a plateau, continued depolarization, or secondary further depolarization. Of 21 cells, only seven fully recovered initial R123 intensities and mitochondrial potential. The contin-
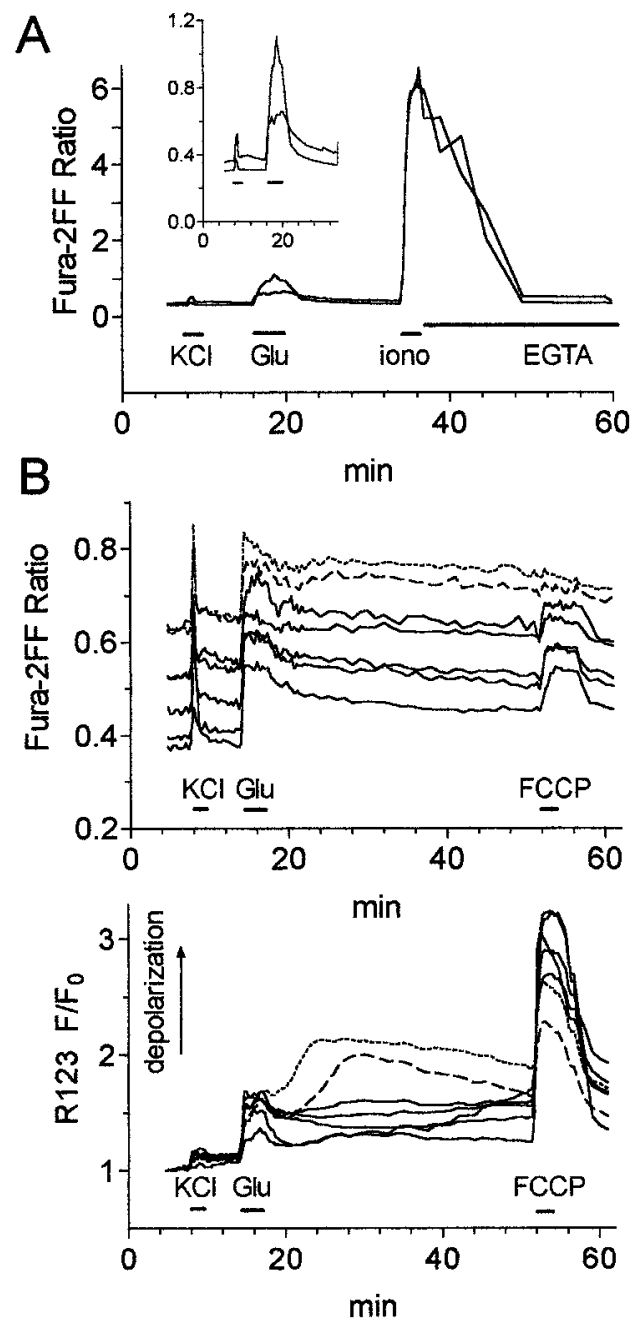

Figure 8. Elevation of cytosolic $\mathrm{Ca}^{2+}$ and depolarization of mitochondrial membrane potential in hippocampal neurons. $A$, In patch-loaded, $\mathrm{K}$-fura-2FF neurons, $\left[\mathrm{Ca}^{2+}\right]_{i}$ rose to a greater extent and remained elevated longer in response to $500 \mu \mathrm{M}$ glutamate than to $50 \mathrm{mM} \mathrm{KCl}$. Inset shows expanded ratio scale for $\mathrm{KCl}$ and glutamate responses. Calibration was accomplished by changing to $10 \mathrm{mM} \mathrm{Ca}^{2+}$-containing recording solution $1 \mathrm{~min}$ before the indicated addition of ionomycin (iono) to determine $\mathrm{R}_{\text {max }}$. A prolonged incubation in recording solution with EGTA and without added $\mathrm{Ca}^{2+}(E G T A)$ returned the ratio to minimal levels for $\mathrm{R}_{\min }$ determination. Peak $\left[\mathrm{Ca}^{2+}\right]_{i}$ levels in response to glutamate for these cells were 9 and $25 \mu \mathrm{M}$. $B$, In neurons loaded with both fura-2FF and R123, mitochondrial depolarization was often associated with sustained elevation of $\left[\mathrm{Ca}^{2+}\right]_{\mathrm{i}}$. Neurons without apparent mitochondrial calcium accumulation appear as broken lines. Data are from seven neurons in a representative experiment.

ued mitochondrial depolarization of the other 14 neurons was consistent with a $\mathrm{Ca}^{2+}$-induced permeability. A brief application of $200 \mathrm{~nm}$ FCCP to fully depolarize mitochondria indicated that $\mathrm{R} 123$ was retained in these cells and that the recoveries observed were real and did not represent dye loss to the media (Dubinsky and Levi, 1998). Mitochondrial depolarization by FCCP also caused release of sequestered mitochondrial calcium to the cytosol (Wang and Thayer, 1996). If the neuronal mitochondria were fully depolarized by glutamate, FCCP would not alter the R123 signal. It is noteworthy that the cells with the most depolarized mitochondria before FCCP did not show any increase in $\left[\mathrm{Ca}^{2+}\right]_{\mathrm{i}}$ to FCCP (Fig. 8 B, dashed lines). The absence of a change in $\left[\mathrm{Ca}^{2+}\right]_{\mathrm{i}}$ in response to $\mathrm{FCCP}$ was observed in 13 of 21 neurons. 
Figure 9. Scheme of permeability pathways in the inner mitochondrial membrane (IMM) and their relationship to metabolism. Components of the TCA cycle appear at the top with emphasis on those substrates and reactions that generate NADH for complex I of the electron transport chain (ETC; in center of diagram of IMM). Components in the IMM are described from left to right. The various substrate transporters $(S T S)$ are responsible for substrate transport into the matrix. The $\mathrm{P}_{\mathrm{i}}$ transporter uses the $\mathrm{H}^{+}$gradient to provide $\mathrm{P}_{\mathrm{i}}$ for ATP production. The $\mathrm{F}_{1} \mathrm{~F}_{0} \mathrm{ATPase}$ uses the oxidatively produced $\mathrm{H}^{+}$gradient to phosphorylate ADP. FCCP uncouples the ETC from oxidative phosphorylation by facilitating $\mathrm{H}^{+}$influx. The ETC uses NADH in complex I and $\mathrm{FADH}_{2}$ in complex II $(S D H)$ to reduce $\mathrm{O}_{2}$ and extrude $\mathrm{H}^{+}$, establishing the mitochondrial electrochemical potential, $\Delta p=\Delta \mathrm{pH}+\Delta \psi$. The adenine nucleotide transporter $(A N T)$ exchanges ADP and ATP across the IMM. The highconductance mitochondrial permeability transition $(m P T)$ is permeable to molecules up to $1500 \mathrm{D}$. The low-conductance $\mathrm{Ca}^{2+}$ activated pathway (bold) described in this paper is permeable to $\mathrm{H}^{+}$and maybe other ions. The $\mathrm{Ca}^{2+}$ uniporter $\left(\mathrm{Ca}^{2+} \mathrm{Uni}\right)$ is the $\mathrm{Ca}^{2+}$ channel of the IMM. The $\mathrm{Na}^{+} / \mathrm{Ca}^{2+}$ exchanger $(N C E)$ is a normal pathway for mitochondrial $\mathrm{Ca}^{2+}$ extrusion that together with the uniporter can lead to $\mathrm{Ca}^{2+}$ cycling. The permeable outer mitochondrial membrane $(O M M)$ contains large-conductance porin channels that may contribute to $\mathrm{mPT}$ formation at points of apposition between the IMM and OMM. Glu, Glutamate; Asp, aspartate; $a K G, \alpha$-ketoglutarate; $A A T$, aspartate amino transferase; Fum, fumarate; Succ, succinate; $S D H$, succinate dehydrogenase; $G D H$, glutamate dehydrogenase.

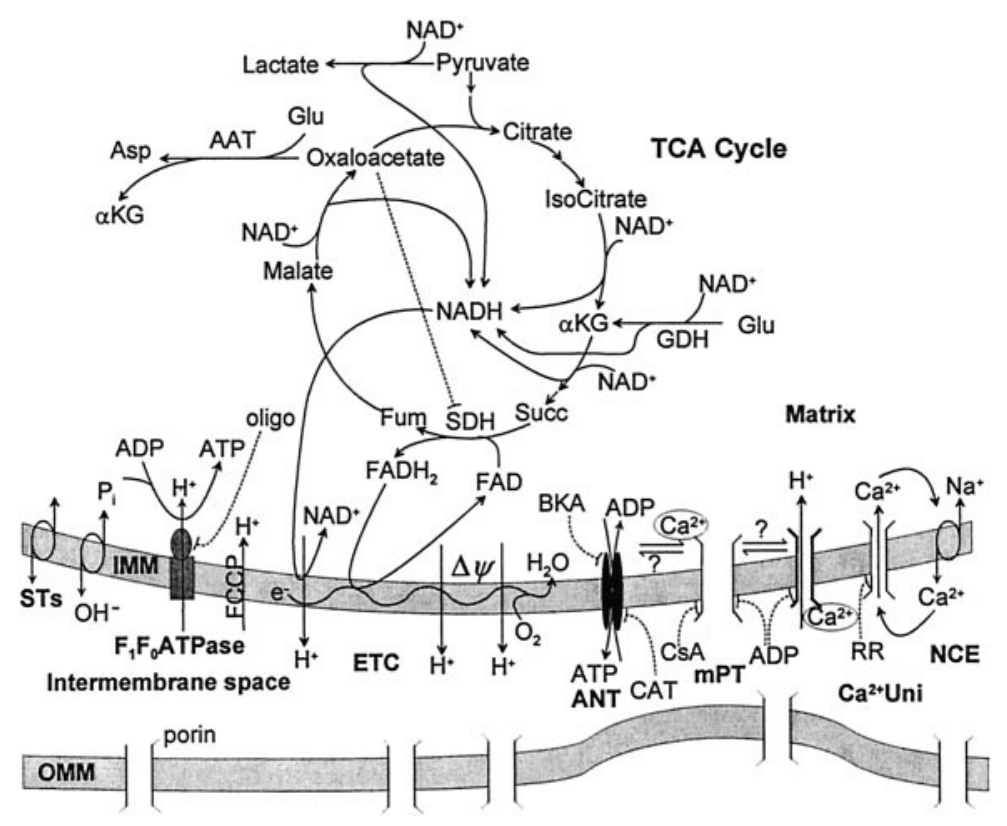

Ten of these 13 neurons were substantially depolarized during and after glutamate treatment. Thus, elevations in cytosolic calcium caused sustained mitochondrial depolarizations, and in over half of the cells these depolarizations prevented calcium accumulation. Definitive identification of the permeability pathway responsible for mitochondrial depolarization in situ awaits development of cell permeant-specific antagonists.

The $100 \mu \mathrm{M} \mathrm{Ca}^{2+}$ challenges used in the isolated mitochondrial experiments could be criticized as high, even for pathological conditions. However, Carriedo et al. (1998), using the lowaffinity calcium dye fura-2FF, recently reported that AMPA- and NMDA-induced elevations in cytosolic $\mathrm{Ca}^{2+}$ reached $60 \mu \mathrm{M}$ in GAD-immunoreactive and 30-50 $\mu \mathrm{M}$ in other cultured murine cortical neurons. We sought to verify this observation in cultured rat hippocampal neurons loaded only with fura-2FF. A 2 min depolarization by $50 \mathrm{~mm} \mathrm{KCl}$ produced only a minor or transient increase in the fura-2FF ratios (Fig. $8 A$ ), whereas $3 \mathrm{~min}$ of exposure to $500 \mu \mathrm{M}$ glutamate produced a substantial increase with a slow recovery. The rate and extent of recovery varied from dish to dish. In 18 fura-2FF AM-loaded neurons without individual calibrations, glutamate produced a maximal $\left[\mathrm{Ca}^{2+}\right]_{\mathrm{i}}$ of $29 \pm$ $3 \mu \mathrm{M}$ (mean \pm SEM, range 7-52 $\mu \mathrm{M}$ ). In 9 fura-2FF AM-loaded neurons with individual calibrations, the peak level of $\left[\mathrm{Ca}^{2+}\right]_{\mathrm{i}}$ attained was $14 \pm 3 \mu \mathrm{M}$ (mean \pm SEM, range 3-37 $\mu \mathrm{M}$ ). In six neurons individually loaded with K-fura-2FF and individually calibrated, the mean peak $\left[\mathrm{Ca}^{2+}\right]_{\mathrm{i}}$ was $16 \pm 3 \mu \mathrm{M}$ (range, 9-22 $\mu \mathrm{M})$. In the latter two cases, if the individual calibrations were ignored and the sister dish values of $\mathrm{R}_{\max }, \mathrm{R}_{\min }$, and $\beta$ were employed, the values calculated for $\left[\mathrm{Ca}^{2+}\right]_{\mathrm{i}}$ were $41 \pm 8 \mu \mathrm{M}$ and $47 \pm 8 \mu \mathrm{M}$, respectively. Higher values of $\left[\mathrm{Ca}^{2+}\right]_{i}$ and correspondingly lower values of $\mathrm{R}_{\max }$ were obtained when the dye intensity was only marginally greater than the background video noise, when background subtraction was inadequate, or when R123 fluorescence bled through into the fura-2FF wavelengths. Our values of $\left[\mathrm{Ca}^{2+}\right]_{\mathrm{i}}$ agree with previous reports that NMDA and glutamate induced increases in $\left[\mathrm{Ca}^{2+}\right]_{\mathrm{i}}$ of $\sim 8-16 \mu \mathrm{M}$ measured with the low-affinity dyes, BTC, calcium green $5 \mathrm{~N}$, and mag-fura-2 (Hyrc et al., 1997; Stout and Reynolds, 1999). They indicate that globally $\left[\mathrm{Ca}^{2+}\right]_{\mathrm{i}}$ may approach the minimum levels $(25 \mu \mathrm{M})$ we tested and found produced sustained mitochondrial depolarization. In addition, $\left[\mathrm{Ca}^{2+}\right]_{\mathrm{i}}$ is nonuniform, changing dynamically during activity in different parts of the cell (Tank et al., 1988; Hernandez-Cruz et al., 1990; Guthrie et al., 1991). In nerve terminals, $\mathrm{Ca}^{2+}$ levels inside the plasma membrane adjacent to voltage-activated $\mathrm{Ca}^{2+}$ channels may reach hundreds of micromolar levels (Simon and Llinas, 1985; Adler et al., 1991). At postsynaptic sites, locally high domains of $\left[\mathrm{Ca}^{2+}\right]_{i}$ may reciprocally influence neighboring mitochondria and eventual cell fate (Tymianski et al., 1993; Budd and Nicholls, 1996; Sattler et al., 1998). Thus, individual mitochondria may experience $\mathrm{Ca}^{2+}$ loads comparable to those used here.

\section{DISCUSSION}

Taken together, these data demonstrate two distinct mitochondrial responses to $100 \mu \mathrm{M} \mathrm{Ca}{ }^{2+}$ that may indicate two different mechanisms of membrane permeabilization (Fig. 9). In the presence of an optimal substrate environment, mitochondria responded in a complex manner, as would be expected of the mPT operating in its classical or high conductance mode, as previously reported for brain mitochondria (Kristal and Dubinsky, 1997). In the presence of restricted substrates, $100 \mu \mathrm{M} \mathrm{Ca}{ }^{2+}$ induced an immediate, sustained mitochondrial depolarization that prevented rapid $\mathrm{Ca}^{2+}$ accumulation and was not associated with large amplitude swelling or an increase in respiration. This may represent selective induction of a low-conductance permeability pathway sensitive to EGTA and ADP. Because sucrose did not permeate sufficiently to produce measurable swelling, the conductance of this permeability must be lower than that of the fully open $\mathrm{mPT}$ pore. Because $\Delta \psi$ is generated by proton translocation, the novel pathway must be at least proton-permeable. However, we cannot rule out translocation of other mono- or divalent cations because the selectivity of this permeability pathway remains unknown. In an optimal substrate environment, higher $\mathrm{Ca}^{2+}$ concentrations produced a sustained depolarization, im- 
mediate increase in respiration, limited $\mathrm{Ca}^{2+}$ uptake, and mitochondrial swelling. This response may reflect combined activation of both the high-conductance $\mathrm{mPT}$ pore and the novel lowconductance pathway.

The mechanism of this $\mathrm{Ca}^{2+}$-induced sustained depolarization is not entirely clear. We have ruled out respiratory insufficiency and activation of $\mathrm{Ca}^{2+}$ cycling as direct causes of the depolarization. The sustained depolarization could be attributable to: (1) opening of only a few high-conductance mPT pores, (2) activation of a substrate of the $\mathrm{mPT}$ pore, or (3) induction of a novel proton-permeable, low-conductance pathway. The ability of agents (CsA and ADP) known to interact with the classical mPT to repolarize mitochondria after the sustained $\mathrm{Ca}^{2+}$-induced depolarization, raises the possibility that this pathway might be linked to the mPT. Both responses in succinate and in succinate plus glutamate were triggered by $\mathrm{Ca}^{2+}$ in a dose-dependent manner. Like the classical $\mathrm{mPT}$, the effect of CsA was overcome at high $\mathrm{Ca}^{2+}$ concentrations.

Opening of only a few high-conductance mPT pores per mitochondria uniformly throughout the mitochondrial population could produce a sustained depolarization without swelling if the rate of sucrose entry was considerably slower than pore opening. The half times for sucrose permeation through open $\mathrm{Ca}^{2+}$ activated $\mathrm{mPT}$ pores in liver mitochondria have been measured to be $0.8-2 \mathrm{sec}$ (Crompton and Costi, 1988; Massari, 1996). We have waited up to $15 \mathrm{~min}$ in conditions producing the sustained depolarization and only observed a small, stable percentage of the maximal swelling in response to $\mathrm{Ca}^{2+}$. Flickering or transient opening of classical mPT pores could permit slow sucrose accumulation that might be counterbalanced by volume regulatory potassium efflux. However, over the extended time period of our observations, the pool of mitochondrial $\mathrm{K}^{+}$would be depleted, and swelling should again be observed. Considering that the $\mathrm{Ca}^{2+}$ challenge was delivered as a concentrated aliquot injected into the stirred mitochondrial suspension, activation of the highconductance $\mathrm{mPT}$ in a small portion of mitochondria initially exposed to this bolus cannot be ruled out. This may account for the stable, small degree of swelling that was observed accompanying the sustained depolarization. However, complete depolarization of only this small population would not produce the observed degree of depolarization. Thus, it appears unlikely that opening of a few, classical mPT pores could account for the sustained depolarization and observed minimal swelling.

It is not clear yet whether the same protein, or complex of proteins, is responsible for the $\mathrm{mPT}$ pore and the lowconductance permeability reported here. The ANT, in association with different mitochondrial proteins, is probably responsible for the high-conductance $\mathrm{mPT}$ pore (Halestrap and Davidson, 1990; Beutner et al., 1998). In patch-clamp experiments on giant proteoliposomes containing reconstituted ANT, a large $\mathrm{Ca}^{2+}$ dependent nonselective channel was detected, characterized, and attributed to the $\mathrm{Ca}^{2+}$-modified ANT (Brustovetsky and Klingenberg, 1996). $\mathrm{Ca}^{2+}$ caused ATP, AMP, and malate release from ANT-containing proteoliposomes, confirming the earlier observations (Beutner et al., 1998; Ruck et al., 1998). The ANTlinked channel possesses multiple conductance states (Brustovetsky and Klingenberg, 1996) resembling the mitochondrial megachannel (Szabo and Zoratti, 1989) or multiconductance channel (Kinnaly et al., 1989) detected in mitoplasts and associated with the mPT pore (Szabo and Zoratti, 1991, 1992; Zorov et al., 1992). Thus, a low-conductance state of the ANT-linked channel could be responsible for the increased ion leakage and mitochondrial depolarization in the absence of swelling. However, in the current experiments, the ANT ligands BKA and CAT were ineffective. If the $\mathrm{mPT}$ contributes to the sustained depolarization, it must be operating in a mode that does not require conformational changes in the ANT. Alternatively, a still unidentified mitochondrial protein could contribute to the $\mathrm{Ca}^{2+}$ stimulated increase of membrane proton permeability. ADP inhibited both the mPT (Hunter and Haworth, 1979; Novgorodov et al., 1992) and the permeability pathway responsible for the sustained depolarization reported here. However, this does not support a single ADP-sensitive mechanism because mitochondria have multiple ADP binding sites. For example, in addition to ANT binding, ADP interacts with a $10 \mathrm{kDa}$ CsA-binding protein in liver mitochondria (Andreeva and Crompton, 1994) and with the $\mathrm{Ca}^{2+}$ uniporter (Litsky and Pfeiffer, 1997). Thus the CATinsensitive ADP repolarization could be mediated by proteins other than the ANT.

A unique aspect of the current work is that this novel pathway was detected under conditions of restricted substrate supply. High respiratory and proton pumping activity of the electron transport chain can compensate for an increase of proton permeability of the inner membrane, preventing depolarization and impeding detection of any permeability changes. Partial inhibition of oxidation and proton-pumping activity together with increased proton permeability could combine to prevent repolarization after $\mathrm{Ca}^{2+}$-induced depolarization. Presumably, the inhibition of succinate oxidation occurred at the level of SDH because of in vitro accumulation of oxaloacetate, a competitive inhibitor of SDH. In the presence of glutamate, oxaloacetate is converted into aspartate in a transamination reaction (Lehninger et al., 1993). In an environment with limited substrates, mitochondria failed to compensate proton influx and restore $\Delta \psi$ caused by partially suppressed SDH. Thus, partial inhibition of SDH unmasked the $\mathrm{Ca}^{2+}$-triggered increased proton permeability of the membrane. Cytosolic $\mathrm{Ca}^{2+}$ may open this low-conductance pathway in all conditions, but only when proton-pumping activity is restricted will mitochondrial depolarization remain uncompensated, revealing activation of the low-conductance permeability.

In diseases involving metabolic restrictions, activation of this novel pathway by $\mathrm{Ca}^{2+}$ may depolarize mitochondria, slow $\mathrm{Ca}^{2+}$ uptake, and effect activation of downstream degenerative pathways. Clinical conditions that might produce restrictions on mitochondrial substrate availability include ischemia, malnutrition, metabolic disorders, and diseases produced by mitochondrial DNA mutations. In addition, metabolic abnormalities have been observed in brain in Parkinson's, Alzheimer's, and Huntington's diseases (Fiskum et al., 1999). In the 3NP model of Huntington's disease, the inhibition of succinate dehydrogenase would be expected to restrict mitochondrial respiration in a manner similar to that observed in the low succinate environment studied here. Energetic restrictions may be clinically relevant in light of recent reports that $\mathrm{CsA}$ is neuroprotective against conditions accompanied by altered energy metabolism, hyperglycemic ischemia, and insulin-induced hypoglycemia (Folbergrova et al., 1997; Li et al., 1997; Friberg et al., 1998). Activation of the sustained mitochondrial depolarization could be viewed as a possible neuroprotective mechanism. By restricting mitochondrial $\mathrm{Ca}^{2+}$ accumulation, induction of the high-conductance $\mathrm{mPT}$ and mitochondrial swelling may be prevented (Stout et al., 1998). Because mitochondrial production of reactive oxygen species is higher in polarized mitochondria when the electron transport chain is more reduced (Skulachev, 1996), depolarization would be expected to decrease 
the amount of ROS produced. Both of these consequences could be beneficial to a cell struggling to regain its homeostasis.

On the other hand, activation of the low-conductance permeability could actually initiate a slower process of degeneration consequent to subtle mitochondrial dysfunction. With respiration limited by the restricted substrate supply, ATP production would be limited and unable to increase in response to stress. $\mathrm{Ca}^{2+}$ induced depolarization may also inhibit transhydrogenase, limiting the NADPH-dependent replenishment of mitochondrial GSH (Nicholls and Ferguson, 1992), effectively lowering antioxidant defenses, and altering sulfhydryl redox status to favor highconductance $\mathrm{mPT}$ induction. Thus, the combination of mitochondrial depolarization and ROS-activated oxidation of critical thiols may make the mitochondria more susceptible to highconductance $\mathrm{mPT}$ activation at lower levels of accumulated $\mathrm{Ca}^{2+}$. Additionally, if mitochondrial $\mathrm{Ca}^{2+}$ uptake became negligible, cytosolic $\mathrm{Ca}^{2+}$ would remain elevated for longer periods of time. This is suggested by the observation in the cultured neurons of prolonged elevation of $\left[\mathrm{Ca}^{2+}\right]_{\mathrm{i}}$ and continued mitochondrial depolarization. More definitive identification of this novel pathway in situ awaits identification of effective cellpermeant antagonists. In this scenario, overstimulation of other $\mathrm{Ca}^{2+}$-activated processes might become the principle effectors of neurodegeneration.

\section{REFERENCES}

Adler EM, Augustine GJ, Duffy SN, Charlton MP (1991) Alien intracellular calcium chelators attenuate neurotransmitter release at the squid giant synapse. J Neurosci 11:1496-1507.

Al-Nasser I, Crompton M (1986) The reversible $\mathrm{Ca}^{2+}$-induced permeabilization of rat liver mitochondria. Biochem J 239:19-29.

Andreeva L, Crompton M (1994) An ADP-sensitive cyclosporin-Abinding protein in rat liver mitochondria. Eur J Biochem 221:261-268.

Andreyev AY, Fahy B, Fiskum G (1998) Cytochrome c release from brain mitochondria is independent of the mitochondrial permeability transition. FEBS Lett 439:373-376.

Ankarcrona M, Dypbukt JM, Orrenius S, Nicotera P (1996) Calcineurin and mitochondrial function in glutamate-induced neuronal cell death. FEBS Lett 394:321-324.

Beatrice MC, Stiers DL, Pfeiffer DR (1982) Increased permeability of mitochondria during $\mathrm{Ca}^{2+}$ release induced by $t$-butyl hydroperoxide or oxaloacetate. The effect of ruthenium red. J Biol Chem. 257:7161-7171.

Bernardi P (1992) Modulation of the mitochondrial cyclosporin A-sensitive permeability transition pore by the proton electrochemical gradient: evidence that the pore can be opened by membrane depolarization. J Biol Chem 267:8834-8839.

Beutner G, Ruck A, Riede B, Brdiczka D (1998) Complex between porin, hexokinase, mitochondrial creatine kinase and adenylate translocator display properties of the permeability transition pore. Implication for regulation of permeability transition by kinases. Biochim Biophys Acta 1368:7-18.

Bradford MM (1976) A rapid and sensitive method for the quantitation of microgram quantities of protein utilizing the principle of protein-dye binding. Anal Biochem 72:248-254.

Broekemeier KM, Pfeiffer DR (1995) Inhibition of the mitochondrial permeability transition by cyclosporin a during long time frame experiments: relationship between pore opening and the activity of mitochondrial phospholipases. Biochemistry 34:16440-16449.

Broekemeier KM, Schmid PC, Schmid HHO, Pfeiffer DR (1985) Effect of phospholipase $\mathrm{A}_{2}$ inhibitors on ruthenium red-induced $\mathrm{Ca}^{2+}$ release from mitochondria. J Biol Chem 260:105-113.

Broekemeier KM, Dempsey ME, Pfeiffer DR (1989) Cyclosporin A is a potent inhibitor of the inner membrane permeability transition in liver mitochondria. J Biol Chem 264:7826-7830.

Broekemeier KM, Klocek CK, Pfeiffer DR (1998) Proton selective substrate of the mitochondrial permeability transition pore: regulation by the redox state of the electron transport chain. Biochemistry $37: 13059-13065$

Brustovetsky N, Klingenberg M (1996) Mitochondrial adp/atp carrier can be reversibly converted into a large channel by $\mathrm{Ca}^{2+}$. Biochemistry 35:8483-8488.

Budd SL, Nicholls DG (1996) Mitochondria, calcium regulation, and acute glutamate excitotoxicity in cultured cerebellar granule cells. J Neurochem 67:2282-2291.

Carriedo SG, Yin HZ, Sensi SL, Weiss JH (1998) Rapid $\mathrm{Ca}^{2+}$ entry through $\mathrm{Ca} 2+$-permeable AMPA/Kainate channels triggers marked intracellular $\mathrm{Ca}^{2+}$ rises and consequent oxygen radical production. J Neurosci 18:7727-7738.

Cassarino DS, Fall CP, Smith TS, Bennett JP (1998) Pramipexole reduces reactive oxygen species production in vivo and in vitro and inhibits the mitochondrial permeability transition produced by the parkinsonian neurotoxin methylpyridinium ion. J Neurochem 71:295-301.

Crompton M, Costi A (1988) Kinetic evidence for a heart mitochondrial pore activated by $\mathrm{Ca}^{2+}$, inorganic phosphate and oxidative stress. A potential mechanism for mitochondrial dysfunction during cellular $\mathrm{Ca}^{2+}$ overload. Eur J Biochem 178:489-501.

Crompton M, Ellinger H, Costi A (1988) Inhibition by cyclosporin A of a $\mathrm{Ca}^{2+}$-dependent pore in heart mitochondria activated by inorganic phosphate and oxidative stress. Biochem J 255:357-360.

Dubinsky JM, Levi Y (1998) Calcium-induced activation of the mitochondrial permeability transition in hippocampal neurons. J Neurosci Res 53:728-741.

Duchen MR (1992) $\mathrm{Ca}^{2+}$-dependent changes in the mitochondrial energetics in single dissociated mouse sensory neurons. Biochem $\mathbf{J}$ 283:41-50.

Ellerby HM, Martin SJ, Ellerby LM, Naiem SS, Rabizadeh S, Salvesen, GS, Casiano CA, Cashman NR, Green DR, Bredesen DE (1997) Establishment of a cell-free system of neuronal apoptosis: comparison of premitochondrial, mitochondrial, and postmitochondrial phases. J Neurosci 17:6165-6178.

Eskes R, Antonsson B, Osensand A, Montessuit S, Richter C, Sadoul R, Mazzei G, Nichols A, Martinou JC (1998) BAX-induced cytochrome $\mathrm{c}$ release from mitochondria is independent of the permeability transition pore but highly dependent on $\mathrm{Mg}^{2+}$ ions. J Cell Biol 143:217-224.

Fiskum G, Murphy AN, Beal MF (1999) Mitochondria in neurodegeneration: acute ischemia and chronic neurodegenerative diseases. J Cereb Blood Flow Metab 19:351-369.

Folbergrova J, Li PA, Uchino H, Smith ML, Siesjo BK (1997) Changes in the bioenergetic state of rat hippocampus during 2.5 min of ischemia, and prevention of cell damage by cyclosporin $\mathrm{A}$ in hyperglycemic subjects. Exp Brain Res 114:44-50.

Fournier N, Ducet G, Crevat A (1987) Action of cyclosporine on mitochondrial calcium fluxes. J Bioenerg Biomembr 19:297-303.

Friberg H, Ferrand-Drake M, Bengtsson F, Halestrap AP, Wieloch T (1998) Cyclosporin A, but not FK 506, protects mitochondria and neurons against hypoglycemic damage and implicates the mitochondrial permeability transition in cell death. J Neurosci 18:5151-5159.

Golovina VA, Blaustein MP (1997) Spatially and functionally distinct $\mathrm{Ca}^{2+}$ stores in sarcoplasmic and endoplasmic reticulum. Science 275:1643-1648.

Green DR, Reed JC (1998) Mitochondria and apoptosis. Science 281:1309-1312.

Grynkiewicz G, Poenie M, Tsien RY (1985) A new generation of $\mathrm{Ca}^{2+}$ indicators with greatly improved fluorescence properties. J Biol Chem 260:3440-3450.

Gunter TE, Pfeiffer DR (1990) Mechanisms by which mitochondria transport calcium. Am J Physiol 258:C755-C786.

Guthrie PB, Segal M, Kater SB (1991) Independent regulation of calcium revealed by imaging dendritic spines. Nature 354:76-80.

Halestrap AP, Davidson AM (1990) Inhibition of $\mathrm{Ca}^{2+}$-induced largeamplitude swelling of liver and heart mitochondria by cyclosporin is probably caused by the inhibitor binding to mitochondrial-matrix peptidyl-prolyl cis-trans isomerase and preventing it interacting with the adenine nucleotide translocase. Biochem J 268:153-160.

Hernandez-Cruz A, Sala F, Adams PR (1990) Subcellular calcium transients visualized by confocal microscopy in a voltage-clamped vertebrate neuron. Science 247:858-862.

Hirsch T, Susin SA, Marzo I, Marchetti P, Zamzami N, Kroemer G (1998) Mitochondrial permeability transition in apoptosis and necrosis. Cell Biol Toxicol 14:141-145.

Hunter DR, Haworth RA (1979) The $\mathrm{Ca}^{2+}$-induced membrane transition in mitochondria. I. The protective mechanisms. Arch Biochem Biophys 195:453-459. 
Hyrc K, Handran SD, Rothman SM, Goldberg MP (1997) Ionized intracellular calcium concentration predicts excitotoxic neuronal death: observations with low-affinity fluorescent calcium indicators. J Neurosci 17:6669-6677.

Ichas F, Jouaville LS, Mazat JP (1997) Mitochondria are excitable organelles capable of generating and conveying electrical and calcium signals. Cell 89:1145-1153.

Kamo N, Muratsugu M, Hongoh R, Kobatake Y (1979) Membrane potential of mitochondria measured with electrode sensitive to tetraphenyl phosphonium and relationship between proton electrochemical potential and phosphorylation potential in steady state. J Membr Biol 49:105-121.

Keller JN, Guo Q, Holtsberg FW, Brucekeller AJ, Mattson MP (1998) Increased sensitivity to mitochondrial toxin-induced apoptosis in neural cells expressing mutant presenilin-1 is linked to perturbed calcium homeostasis and enhanced oxyradical production. J Neurosci 18:4439-4450.

Kinnaly KW, Campo ML, Tedeschi H (1989) Mitochondrial channel activity studied by patch-clamping mitoplasts. J Bioenerg Biomembr 21:497-506.

Klingenberg M (1985) The ADP/ATP carrier in mitochondrial membranes. In: Bioenergetics of electron and proton transport (Martonosi AN, ed), pp 511-551. New York: Plenum.

Kristal BS, Dubinsky JM (1997) Mitochondrial permeability transition in the central nervous system: induction by calcium-cycling dependent and independent pathways. J Neurochem 69:524-538.

Lehninger AL, Nelson DL, Cox MM (1993) Principles of biochemistry, Ed 2. New York: Worth.

LeQuoc K, LeQuoc D (1988) Involvement of the ADP/ATP carrier in calcium-induced perturbations of the mitochondrial inner membrane permeability: an importance of the orientation of the nucleotide binding site. Arch Biochem Biophys 265:249-257.

Li PA, Uchino H, Elmer E, Siesjo BK (1997) Amelioration by cyclosporin A of brain damage following 5 or $10 \mathrm{~min}$ of ischemia in rats subjected to preischemic hyperglycemia. Brain Res 753:133-140.

Litsky ML, Pfeiffer DR (1997) Regulation of the mitochondrial Ca2+ uniporter by external adenine nucleotides: the uniporter behaves like a gated channel which is regulated by nucleotides and divalent cations. Biochemistry 36:7071-7080.

Liu X, Kim CN, Yang J, Jemmerson R, Wang X (1996) Induction of apoptotic program in cell-free extracts: requirement for dATP and cytochrome c. Cell 86:147-157.

Massari S (1996) Kinetic analysis of the mitochondrial permeability transition. J Biol Chem 271:31942-31948.

Murphy AN, Wang G, Richards CM (1998) Further characterization of mitochondrial cytochrome $\mathrm{C}$ release and inhibition by BCL-2. Soc Neurosci Abstr 24:1945.

Nicholls DG, Ferguson SJ (1992) Bioenergetics 2. London: Academic.

Novgorodov SA, Gudz TI, Jung DW, Brierley GP (1991) The nonspecific inner membrane pore of liver mitochondria: modulation of cyclosporin sensitivity by ADP at carboxyatractyloside-sensitive and insensitive sites. Biochem Biophys Res Commun 180:33-38.

Novgorodov SA, Gudz TI, Milgrom YM, Brierly GP (1992) The permeability transition in heart mitochondria is regulated synergistically by ADP and cyclosporin A. J Biol Chem 267:16274-16282.

Oestreicher AB, Van den Bergh SG, Slater EC (1969) The inhibition by 2,4-dinitrophenol of the removal of oxaloacetate formed by the oxidation of succinate by rat-liver and -heart mitochondria. Biochim Biophys Acta 180:45-55.

Papa S, Lofrumento NE, Paradies G, Quagliariello E (1969) Mechanism of inhibition by uncouples of succinate oxidation in isolated mitochondria. Biochim Biophys Acta 180:35-44.

Reed PW, Lardy HA (1972) A23187: a divalent cation ionophore. J Biol Chem. 247:6970-6977.

Ruck A, Dolder M, Walliman T, Brdiczka D (1998) Reconstituted adenine nucleotide translocase forms a channel for small molecules com- parable to the mitochondrial permeability transition pore. FEBS Lett 426:97-101.

Sattler R, Charlton MP, Hafner M, Tymianski M (1998) Distinct influx pathways, not calcium load, determine neuronal vulnerability to calcium neurotoxicity. J Neurochem 71:2349-2364.

Savage MK, Reed DJ (1994) Release of mitochondrial glutathione and calcium by a cyclosporin A-sensitive mechanism occurs without large amplitude swelling. Arch Biochem Biophys 315:142-152.

Schinder AF, Olson EC, Spitzer NC, Montal M (1996) Mitochondrial dysfunction is a primary event in glutamate neurotoxicity. J Neurosci 16:6125-6133.

Shimizu S, Narita M, Tsujimoto Y (1999) Bcl-2 family proteins regulate the release of apoptogenic cytochrome $\mathrm{c}$ by the mitochondrial channel VDAC. Nature 399:483-487.

Simon SM, Llinas RR (1985) Compartmentalization of the submembrane calcium activity during calcium influx and its significance in transmitter release. Biophys J 48:485-498.

Skulachev VP (1996) Role of uncoupled and non-coupled oxidations in maintenance of safely low levels of oxygen and its one-electron reductants. Q Rev Biophys 29:169-202.

Stout AK, Reynolds IJ (1999) High-affinity calcium indicators underestimate increases in intracellular calcium concentrations associated with excitotoxic glutamate stimulations. Neuroscience 89:91-100.

Stout AK, Raphael HM, Kanterewicz BI, Klann E, Reynolds IJ (1998) Glutamate-induced neuron death requires mitochondrial calcium uptake. Nat Neurosci 1:366-373.

Szabo I, Zoratti M (1989) The inner mitochondrial membrane contains ion-conducting channels similar to those found in bacteria. FEBS Lett 259:137-143

Szabo I, Zoratti M (1991) The giant channel of the inner mitochondrial membrane is inhibited by cyclosporin A. J Biol Chem 266:3376-3379.

Szabo I, Zoratti M (1992) The mitochondrial megachannel is the permeability transition pore. J Bioenerg Biomembr 24:111-117.

Takeuchi Y, Morii H, Tamura M, Hayashi O, Watanabe T (1991) A possible mechanism of mitochondrial dysfunction during cerebral ischemia: inhibition of mitochondrial respiratory activity by arachidonic acid. Arch Biochem Biophys 289:33-38.

Tank DW, Sugimori M, Connor JA, Llinas RR (1988) Spatially resolved calcium dynamics of mammalian Purkinje cells in cerebellar slice. Science 242:773-777.

Tymianski M, Charlton MP, Carlen PL, Tator CH (1993) Source specificity of early calcium neurotoxicity in cultured embryonic spinal neurons. J Neurosci 13:2085-2104.

Vodyanoy I, Bezrukov SM, Colombini M (1992) Measurement of ion channel access resistance. FASEB J 6:A114.

Wang GJ, Thayer SA (1996) Sequestration of glutamate-induced Ca2+ loads by mitochondria in cultured rat hippocampal neurons. J Neurophysiol 76:1611-1621.

White RJ, Reynolds IJ (1996) Mitochondrial depolarization in glutamate-stimulated neurons: an early signal specific to excitotoxin exposure. J Neurosci 16:5688-5697.

Wojtczak AB (1969) Inhibitory action of oxaloacetate on succinate oxidation in rat-liver mitochondria and the mechanism of its reversal. Biochim Biophys Acta 172:52-65.

Zamzami N, Susin SA, Marchetti P, Hirsch T, Gomez-Monterrey I, Castedo M, Kroemer G (1996) Mitochondrial control of nuclear apoptosis. J Exp Med 183:1533-1544.

Zamzami N, Brenner C, Marzo I, Susin SA, Kroemer G (1998) Subcellular and submitochondrial mode of action of Bcl-2-like oncoproteins. Oncogene 16:2265-2282.

Zoratti M, Szabo I (1995) The mitochondrial permeability transition. Biochim Biophys Acta 1241:139-176.

Zorov DB, Kinnaly KW, Tedeschi H (1992) Voltage activation of heart inner mitochondrial membrane channels. J Bioenerg Biomembr 24: $119-124$. 